\title{
The Study of Laccase Immobilization Optimization and Stability Improvement on CTAB-KOH Modified Biochar
}

\section{Zhaobo Wang}

Wuhan University of Science and Technology

Dajun Ren ( $\nabla$ dj_ren@163.com )

Wuhan University of Science and Technology

Shan Jiang

Wuhan University of Science and Technology

Hongyan Yu

Wuhan University of Science and Technology

Yaohui Cheng

Wuhan University of Science and Technology

Shuqin Zhang

Wuhan University of Science and Technology

Xiaoqing Zhang

Wuhan University of Science and Technology

Wangsheng Chen

Wuhan University of Science and Technology

\section{Research Article}

Keywords: laccase, modified biochar, immobilization optimization, stability improvement

Posted Date: May 24th, 2021

DOI: https://doi.org/10.21203/rs.3.rs-151978/v2

License: (1) (1) This work is licensed under a Creative Commons Attribution 4.0 International License.

Read Full License

Version of Record: A version of this preprint was published at BMC Biotechnology on August 5th, 2021. See the published version at https://doi.org/10.1186/s12896-021-00709-3. 
1 The study of laccase immobilization optimization and stability

2 improvement on CTAB-KOH modified biochar

3 Zhaobo Wang ${ }^{\mathrm{a}, \mathrm{b}}$, Dajun Ren*, a,b, Shan Jiang ${ }^{\mathrm{a}, \mathrm{b}}$, Hongyan Yu ${ }^{\mathrm{a}, \mathrm{b}}$, Yaohui Cheng, ${ }^{\mathrm{a}, \mathrm{b}}$, Shuqin

4 Zhang $^{\mathrm{a}, \mathrm{b}}$, Xiaoqing Zhang ${ }^{\mathrm{a}, \mathrm{b}}$, Wangsheng Chen ${ }^{\mathrm{a}, \mathrm{b}}$

5 a College of Resource and Environmental Engineering, Wuhan University of Science and Technology,

6 Wuhan, 430081, China

7

${ }^{b}$ Hubei Key Laboratory for Efficient Utilization and Agglomeration of metallurgic Mineral Resources, Wuhan University of Science and Technology, Wuhan, Hubei 430081, China

\section{Abstract}

Background: Although laccase has a good catalytic oxidation ability, free laccase shows a poor stability. Enzyme immobilization is a common method to improve enzyme stability and endow the enzyme with reusability. Adsorption is the simplest and common method. Modified biochar has attracted great attention due to its excellent performance.

Results: In this paper, cetyltrimethylammonium bromide (CTAB)-KOH modified biochar (CKMB) was used to immobilize laccase by adsorption method (laccase@CKMB). Based on the results of the singlefactor experiments, the optimal loading conditions of laccase@CKMB were studied with the assistance of Design-Expert 12 and response surface methods. The predicted optimal experimental conditions were laccase dosage $1.78 \mathrm{mg} / \mathrm{mL}, \mathrm{pH} 3.1$ and $312 \mathrm{~K}$. Under these conditions, the activity recovery of laccase@CKMB was the highest, reaching 61.78 \%. Then, the CKMB and laccase@CKMB were characterized by TGA, FT-IR, XRD, BET and SEM, and the results showed that laccase could be well immobilized on CKMB, the maximum enzyme loading could reach $57.5 \mathrm{mg} / \mathrm{g}$. Compared to free laccase, the storage and pH stability of laccase@CKMB was improved greatly. The laccase@CKMB retained about $40 \%$ of relative activity $\left(4{ }^{\circ} \mathrm{C}, 30\right.$ days) and more than $50 \%$ of relative activity at $\mathrm{pH} 2-6$. In addition, the laccase@CKMB indicated the reusability up to 6 reaction cycles while retaining $45.1 \%$ of relative activity.

${ }^{*}$ Corresponding authors at: College of Resource and Environmental Engineering, Wuhan University of Science and Technology, Wuhan, 430081, China

E-mail addresses: dj_ren@163.com. Tel.: +86-27-6886-2029; Fax: +86-27-6886-2029. 
Moreover, the thermal deactivation kinetic studies of laccase@CKMB showed a lower k value $(0.00275$ $\left.\min ^{-1}\right)$ and higher $\mathrm{t}_{1 / 2}$ values $(252.0 \mathrm{~min})$ than the $\mathrm{k}$ value $\left(0.00573 \mathrm{~min}^{-1}\right)$ and $\mathrm{t}_{1 / 2}$ values $(121.0 \mathrm{~min})$ of free laccase.

Conclusions: We explored scientific and reasonable immobilization conditions of laccase@CKMB, and the laccase@CKMB possessed relatively better stabilities, which gave the immobilization of laccase on this cheap and easily available carrier material the possibility of industrial applications.

Keywords: laccase; modified biochar; immobilization optimization; stability improvement

\section{Background}

Laccase is a widely distributed copper oxidase, which belongs to ligninase like lignin peroxidase (LiP) and manganese peroxidase $(\mathrm{MnP})$ [1]. The active center of laccase is three types of four copper atoms, including one type I copper atom (T1), one type II copper atom (T2) and two type III copper atoms (T3) [2]. The catalytic mechanism of laccase can be roughly described as T1 takes electrons from the oxidized substrate and transfers them to T2/T3; T2/T3 combines with oxygen atom to reduce $\mathrm{O}_{2}$ to $\mathrm{H}_{2} \mathrm{O}$ [3]. The substrate spectrum of laccase is very rich, including arylamines, aromatic thiols and substituted phenols, which shows the application potential of laccase in the environmental field [4]. In general, laccase is capable of oxidizing phenolic pollutants, PAHs and contaminating pharmaceuticals, with $\mathrm{H}_{2} \mathrm{O}$ as the only byproduct [5-7]. Although laccase has a good catalytic oxidation ability, free laccase shows extremely high sensitivity to environmental conditions, which means that the stability of laccase is poor under natural conditions. Enzyme immobilization is a common method to improve enzyme stability and endow the enzyme with reusability. traditionally classified into entrapment/encapsulation, covalent bonding, cross-linking and adsorption methods. Among the existing laccase immobilization methods, adsorption is the simplest and common method. In recent years, bentonite, activated carbon, metal organic frameworks (MOFs), biochar and chitosan are some attractive carrier materials. $[\underline{8-13}]$. Biochar has attracted great attention due to its large specific surface area, porous, low-cost and easy availability. In additon, another attractive reason for biochar is that it can can be modified by certain methods to enhance its performance, such as alkali modification and acid modification. Jin et al. used $\mathrm{KOH}$ to modify the biochar, and the results showed that the specific surface area increased from $14.4 \mathrm{~m}^{2} / \mathrm{g}$ to $49.1 \mathrm{~m}^{2} / \mathrm{g}$. The adsorption capacity of modified biochar has increased by 
almost 1.5 times compared with before, and the maximum adsorption capacity has been increased from $21.12 \mathrm{mg} / \mathrm{g}$ to $50.71 \mathrm{mg} / \mathrm{g}$ [14]. Peng et al. used phosphoric acid to modify biochar, and the results showed that the specific surface area of the modified biochar was larger, and the adsorption performance of $\mathrm{Cu}^{2+}$ and $\mathrm{Cd}^{2+}$ was better [15].

In recent years, there have been many examples of improving the stability and reusability of laccase by adsorption-immobilized laccase, such as Taheran et al. immobilized laccase onto homemade polyacrylonitrile-biochar composite nanofibrous membrane, and the results showed a good storage, temperature and $\mathrm{pH}$ stability improvement. In addition, the immobilized laccase retained $50 \%$ of relative activity after 7 ABTS oxidation cycles [16]. Moreover, Li et al. achieved a good immobilization of laccase on maple biochar via adsorption method. The results showed the enzyme loading was $11.14 \mathrm{mg} / \mathrm{g}$ and the thermostability of laccase was significantly improved. The maple biochar immobilized laccase retained $30 \%$ of relative activity after 7 reaction cycle [17]. However, the studies on the improvement of stability and reusability of immobilized laccase on cetyltrimethylammonium bromide (CTAB)-KOH modified biochar (CKMB) have not been reported. In this work, the laccase was immobilized onto CKMB via simple adsorption method, the optimization of immobilization was studied via Design-Expert 12 and the properties of free laccase (FL) and immobilized laccase (laccase@CKMB) were compared. In addition, the reusability performance of laccase@CKMB was investigated.

\section{Results}

\section{Characterization analysis}

The thermogravimetric analysis (TGA) curves are performed to examine the thermal properties of FL, CKMB and laccase@CKMB with a constant heating rate of $10{ }^{\circ} \mathrm{C} / \mathrm{min}$ from 25 to $800{ }^{\circ} \mathrm{C}$ under $\mathrm{N}_{2}$ (Fig. 1). There are two weight-losses from 30 to $150{ }^{\circ} \mathrm{C}$ and $>250{ }^{\circ} \mathrm{C}$ for the $\mathrm{FL}$, the first weight-loss is corresponding to the removal of structural water and the second weight-loss is corresponding to the pyrolysis of laccase. The curves of CKMB and laccase@CKMB are similar and both have good thermal stability. The weightlosses of CKMB and laccase@CKMB can be also divided into 30 to $150{ }^{\circ} \mathrm{C}$ and $>250{ }^{\circ} \mathrm{C}$. The first stage is mainly the loss of crystallization or free water in the structure, the second stage is mainly the pyrolysis of CKMB and laccase, this is also the reason why the weight-loss of laccase@CKMB is greater. In addition, the change of temperature range may be due to the high thermal stability of laccase@CKMB, which may be related to the thermal decomposition of laccase and the effective immobilization of laccase [18]. 


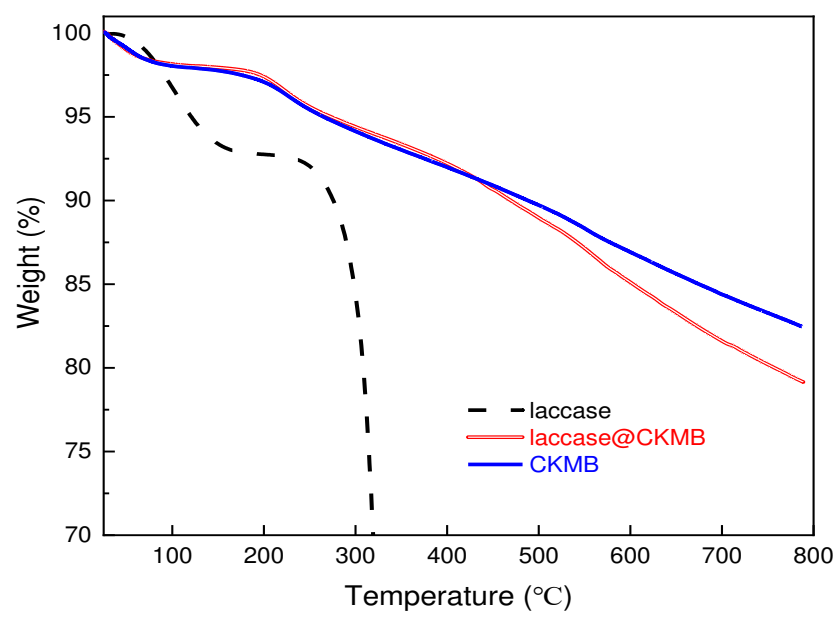

Fig. 1 The TGA curve of CKMB and laccase@CKMB.

According to the analysis of the infrared spectrum (Fig. 2a), the common peak positions of CKMB, FL and laccase@CKMB are at 3440, 2920 and $1050 \mathrm{~cm}^{-1}$. Among them, the broad peak at $3440 \mathrm{~cm}^{-1}$ is the stretching vibration peak of the intermolecular hydrogen bond $\left(\mathrm{v}_{\mathrm{OH}}\right)$ of multi-molecule association [19]; the peak at $2920 \mathrm{~cm}^{-1}$ is the stretching vibration peak of $\mathrm{v}_{\mathrm{asCH}}$, indicating that it contains a saturated hydrocarbon group -CH2 - [20]; The broad peak at $1050 \mathrm{~cm}^{-1}$ is the stretching vibration peak of the hydroxyl group (UCo), which may contain primary alcohols. The peak at $1645 \mathrm{~cm}^{-1}$ in the infrared spectrum of FL represents the stretching vibration peak of $\mathrm{C}-\mathrm{H}$, indicating that it contains unsaturated hydrocarbon groups $\mathrm{C}=\mathrm{C}[\underline{21}]$; the peak at $2850 \mathrm{~cm}^{-1}$ in the infrared spectrum of CKMB is the stretching of $\mathrm{U}_{\mathrm{sCH}}$, indicating that it contains saturated hydrocarbon group - $\mathrm{CH} 2-$, which is a sign of the successful grafting of the quaternary ammonium cation in CTAB to the surface of biochar . In addition, the infrared spectra of laccase@CKMB all contained the above peaks, indicating that laccase was successfully immobilized on the surface of biochar. The CKMB and laccase@CKMB are characterized by X-ray diffraction. The XRD patterns (Fig. 2b) of CKMB and laccase@CKMB samples do not show any significant differences, indicates that the immobilization process of laccase did not affect the structure of CKMB. In addition, Biochar has a disordered structure of amorphous phase, which is mainly caused by the uneven pyrolysis of molecules in the pyrolysis process of biochar [22]. 

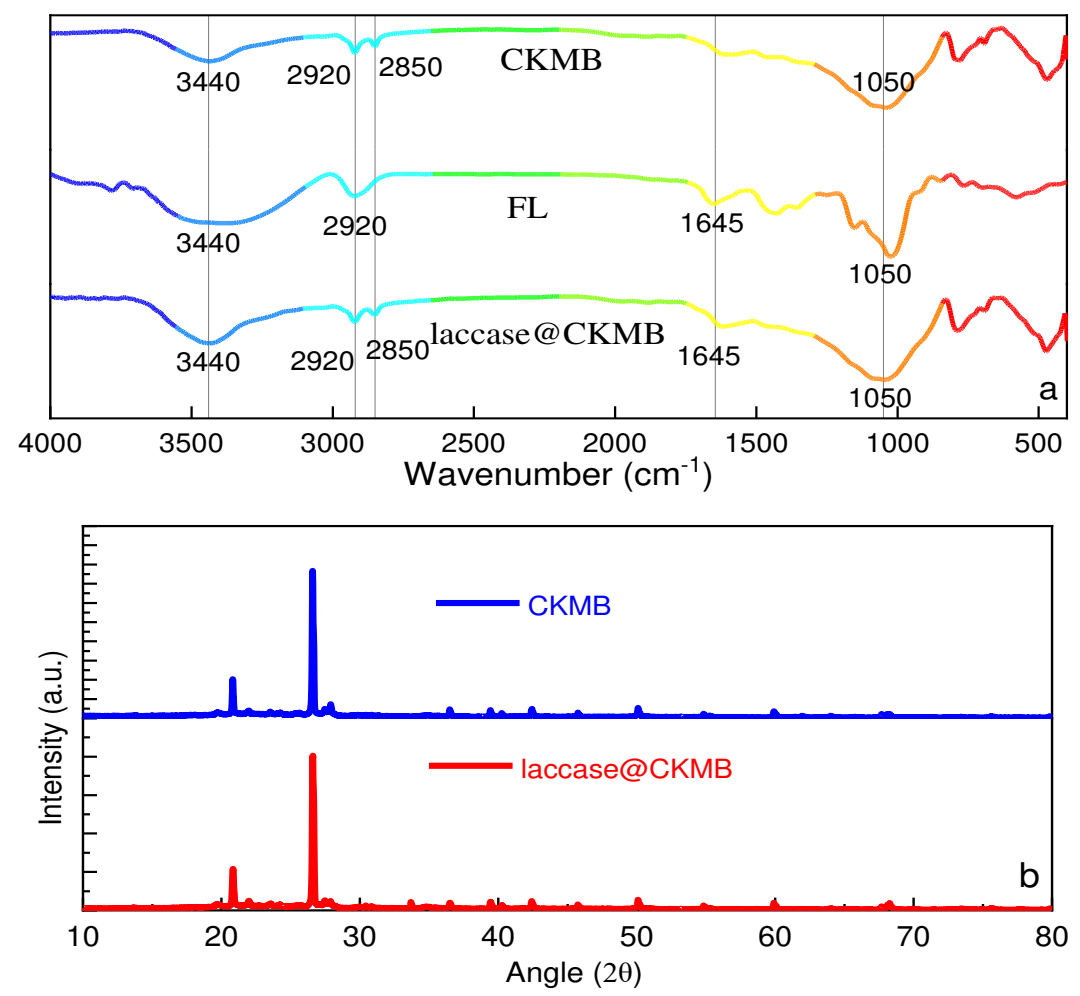

Fig. 2 (a) The FTIR spectra of FL, CKMB and laccase@CKMB. (b) XRD patterns of CKMB and laccase@CKMB.

The results of BET (Fig. 3a) show the $\mathrm{S}_{\text {BET }}$ of CKMB was $221.352 \mathrm{~m}^{2} / \mathrm{g}, \mathrm{S}_{\text {mic }}$ was $87.135 \mathrm{~m}^{2} / \mathrm{g}, \mathrm{V}_{\text {total }}$ was $0.459 \mathrm{~m}^{3} / \mathrm{g}, \mathrm{V}_{\text {mic }}$ was $0.160 \mathrm{~m}^{3} / \mathrm{g}$, and the average pore size was $7.64 \mathrm{~nm}$. It can be seen fromFig. $3 \mathrm{~b}$ that the adsorption-desorption curves of CKMB do not overlap 100\%, the adsorption curve has a clear hysteresis, and there is an inflection point in the low phase region. According to the capillary aggregation phenomenon, this indicates that CKMB contains a small amount of mesopores and macropores. The scanning electron micrographs of CKMB as well as laccase loaded CKMB are given as Fig. 3 c,d,e and f. Fig. 3 c/d and Fig. 3 e/f represent CKMB before and after laccase immobilization, respectively. The surface texture of the immobilized laccase did not change clearly. However, agglomeration phenomenon was observed after the laccase was immobilized with CKMB, which could be attributed to the change in surface charge [23].
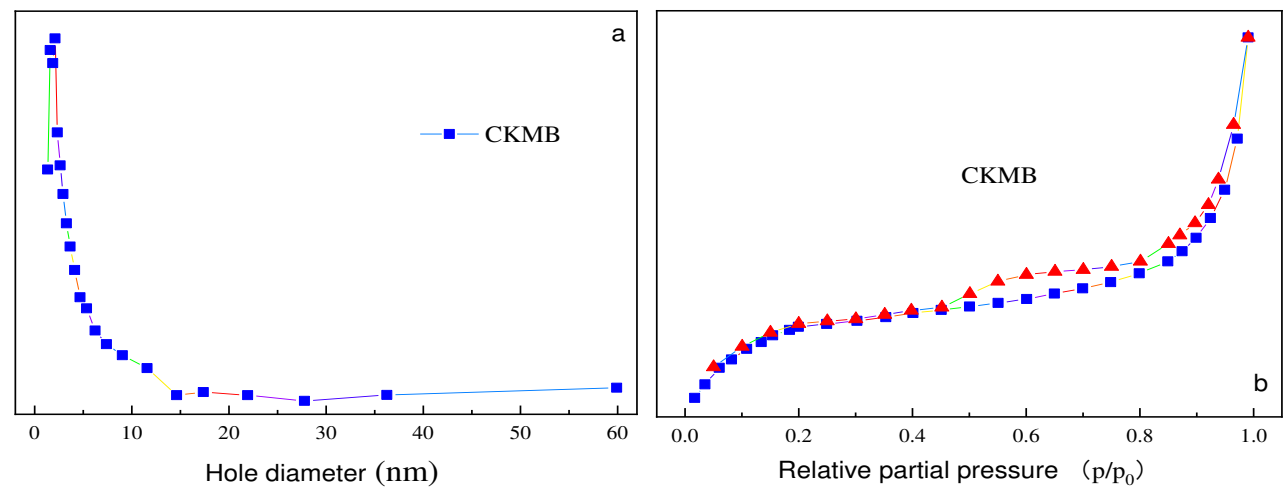

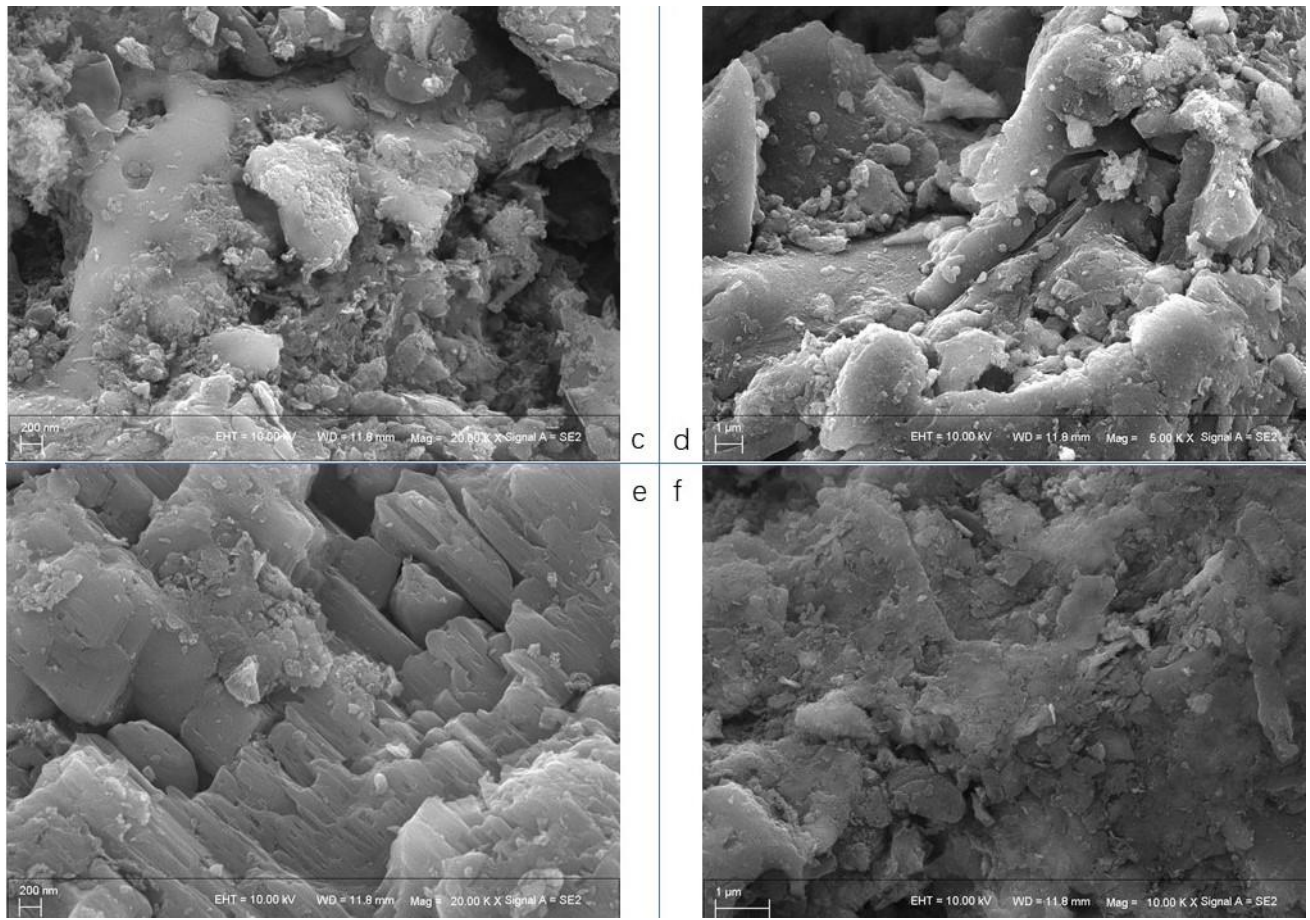

Fig. 3 (a) The pore size distribution of CKMB. (b) The $\mathrm{N}_{2}$ adsorption-desorption curve of CKMB. Scanning electron micrograph of

(c and d) CKMB, (e and f) laccase@CKMB.

\section{Optimal immobilization conditions of laccase@CKMB}

\section{The influence of single-factor on the immobilization effect}

The laccase dosage is the parameter directly related to the cost, and a relatively suitable laccase dosage means a reduction in cost. It could be seen from Fig. 4a that the AR and enzyme loading of laccase@CKMB had the similar changing trends. When the laccase dosage was increased from $0.25 \mathrm{mg} / \mathrm{mL}$ to $1.25 \mathrm{mg} / \mathrm{mL}$, the enzyme loading was increased from $3.5 \mathrm{mg} / \mathrm{g}$ to $34.2 \mathrm{mg} / \mathrm{g}$. At this time, the enzyme loading was close to the peak value. As shown in Fig. 4b, in the pH range of 2-8, the AR of laccase@CKMB reached a maximum of $55.1 \%$ near $\mathrm{pH} 3$. At $\mathrm{pH}=4$, the enzyme loading reached a maximum of $38.2 \mathrm{mg} / \mathrm{g}$, and then showed a downward trend, which was very obvious. The most influential factor in actual industrial applications is the reaction environment temperature. As shown in Fig. 4c, the AR changes of laccase@CKMB all presented a "bell-shaped" distribution. The AR of laccase@CKMB reached a maximum of $61.7 \%$ at $313 \mathrm{~K}$. The enzyme loading was increasing with temperature, rising to the maximum value of $57.5 \mathrm{mg} / \mathrm{g}$ at $333 \mathrm{~K}$. 

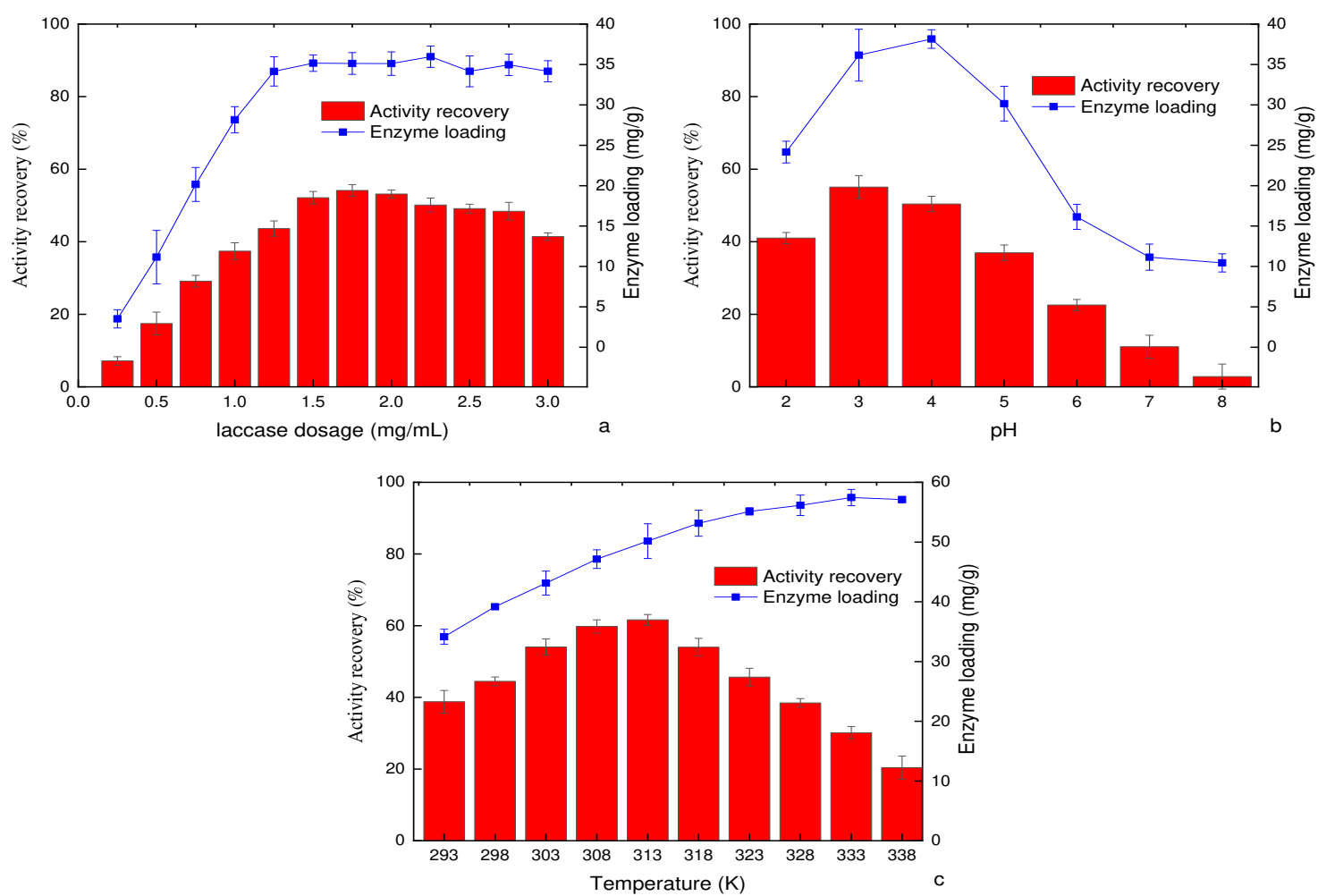

Fig. 4 The effect of (a) laccase dosage, (b) pH and (c) temperature on the immobilization effect.

\section{Optimization of laccase immobilization via Design-Expert}

On the basis of above single-factor experiment results, we designed a three-factor three-level response surface test of laccase dosage (A, 1-3 mg/mL), $\mathrm{pH}(\mathrm{B}, 2-4)$ and temperature (C, 313-323 K) using DesignExpert 12 (Stat-Ease, Inc, Minneapolis, MN, USA). Table 1 listed the coded $(-1,0,+1)$ and actual values of the independent factors, and a total of 17 experimental runs were shown in Table 2, including 5 center points

139 per block.

Table 1 The coded levels of the independent variables in the application of the Box-Behnken design for laccase@CKMB.

\begin{tabular}{cccccccccc}
\hline Factor & Name & Units & Type & Minimum & Maximum & Coded Low & Coded High & Mean & Std. Dev. \\
\hline A & laccase dosage & $\mathrm{mg} / \mathrm{mL}$ & Numeric & 1.0 & 2.5 & -1 & +1 & 1.75 & 0.7071 \\
$\mathrm{~B}$ & $\mathrm{pH}$ & & Numeric & 2.0 & 4.0 & -1 & +1 & 3.0 & 0.7071 \\
$\mathrm{C}$ & temperature & $\mathrm{K}$ & Numeric & 303 & 323 & -1 & +1 & 313 & 7.07 \\
\hline
\end{tabular}

Table 2 Box-Behnken experimental design and recovery activity of laccase@CKMB.

\begin{tabular}{ccccc}
\hline & $\mathrm{A}$ & $\mathrm{B}$ & $\mathrm{C}$ & $\mathrm{Y}$ \\
\cline { 2 - 5 } Run & laccase dosage & $\mathrm{pH}$ & temperature & activity recovery (\%) \\
\hline 1 & 1 & -1 & 0 & 41.23 \\
2 & 0 & 1 & 1 & 40.65
\end{tabular}




\begin{tabular}{|c|c|c|c|c|}
\hline 3 & 0 & 0 & 0 & 61.73 \\
\hline 4 & 0 & 1 & -1 & 39.23 \\
\hline 5 & -1 & 0 & 1 & 32.84 \\
\hline 6 & 1 & 1 & 0 & 46.29 \\
\hline 7 & 0 & 0 & 0 & 63.02 \\
\hline 8 & 0 & 0 & 0 & 60.29 \\
\hline 9 & 1 & 0 & 1 & 36.67 \\
\hline 10 & -1 & 0 & -1 & 43.49 \\
\hline 11 & 0 & -1 & -1 & 40.29 \\
\hline 12 & 0 & 0 & 0 & 62.52 \\
\hline 13 & 0 & 0 & 0 & 59.99 \\
\hline 14 & -1 & 1 & 0 & 44.24 \\
\hline 15 & -1 & -1 & 0 & 40.23 \\
\hline 16 & 1 & 0 & -1 & 42.07 \\
\hline 17 & 0 & -1 & 1 & 30.61 \\
\hline
\end{tabular}

142 We adopted the central combination model to conduct a three-factor three-level response surface 143 analysis test. The results from Table 3 showed that factor coding is coded and sum of squares is type III144 Partial. In addition, the Model F-value of 98.88 implied the model is significant. There was only a $0.01 \%$ 145 chance that an F-value this large could occur due to noise. P-values $<0.0500$ indicate model terms are 146 significant. In this case $\mathrm{B}, \mathrm{C}, \mathrm{BC}, \mathrm{A}^{2}, \mathrm{~B}^{2}, \mathrm{C}^{2}$ are significant model terms (P-values $>0.1000$ indicated the 147 model terms were not significant). Where A was laccase dosage, B was $\mathrm{pH}$ and $\mathrm{C}$ was temperature. The Lack 148 of Fit F-value of 1.42 and P-value of 0.3595 indicated the Lack of Fit is not significant relative to the pure 149 error, which proved the mathematical regression model was reliable. It could also be seen from the F-value 150 that the order of the influence of each factor on the change of the AR in the experiment was: temperature 151 (C) $>\mathrm{pH}(\mathrm{B})>$ laccase dosage (A). The quadratic polynomial regression model was estimated using Design152 Expert 12 for the AR of laccase@CKMB is $\mathrm{Y}=61.51+0.6825 \mathrm{~A}+2.26 \mathrm{~B}-3.04 \mathrm{C}+0.2625 \mathrm{AB}-$ $153 \quad 1.31 \mathrm{AC}+2.78 \mathrm{BC}-8.72 \mathrm{~A}^{2}-9.79 \mathrm{~B}^{2}-14.02 C^{2}$.

154 Table 3 The analysis of variance (ANOVA) for the fitted quadratic polynomial model of laccase@CKMB.

\begin{tabular}{cccccc}
\hline Source & Sum of Squares & df & Mean Square & F-value & p-value \\
\hline Model & 1879.61 & 9 & 208.85 & 98.88 & $<0.0001$ \\
A & 3.73 & 1 & 3.73 & 1.76 & 0.2258 \\
B & 40.73 & 1 & 40.73 & 19.28 & 0.0032 \\
C & 73.87 & 1 & 73.87 & 34.97 & 0.0006
\end{tabular}




\begin{tabular}{|c|c|c|c|c|c|c|}
\hline $\mathrm{AB}$ & 0.2756 & 1 & 0.2756 & 0.1305 & 0.7286 & \\
\hline $\mathrm{AC}$ & 6.89 & 1 & 6.89 & 3.26 & 0.1138 & \\
\hline $\mathrm{BC}$ & 30.80 & 1 & 30.80 & 14.58 & 0.0066 & \\
\hline $\mathrm{A}^{2}$ & 320.16 & 1 & 320.16 & 151.58 & $<0.0001$ & \\
\hline $\mathrm{B}^{2}$ & 403.76 & 1 & 403.76 & 191.16 & $<0.0001$ & \\
\hline $\mathrm{C}^{2}$ & 827.92 & 1 & 827.92 & 391.98 & $<0.0001$ & \\
\hline Residual & 14.79 & 7 & 2.11 & & & \\
\hline Lack of Fit & 7.64 & 3 & 2.55 & 1.42 & 0.3595 & not significant \\
\hline Pure Error & 7.15 & 4 & 1.79 & & & \\
\hline Cor Total & 1894.39 & 16 & & & & \\
\hline
\end{tabular}

In order to describe the individual and cumulative effects of independent variables on the response, Design-Expert 12 was used to graphically represent the fitted polynomial equations as response surfaces and contour plots (Fig. 5). Based on the RSM and estimated regression coefficient, we gave the optimal value of the selected variable. The AR of laccase@CKMB was related to laccase dosage to a certain degree (Fig. $5 \mathrm{a}$ and $\mathrm{b}$ ). Excessive laccase dosage could lead to lack of space between molecules (steric hindrance), which resulted in mass transfer limitation [24]. This obstacle was due to too many enzymes on the surface of the carrier, which limited the dispersion of substrates and products [25]. The effect of $\mathrm{pH}$ on the AR of laccase@CKMB was shown in Fig. 5a and c. It could be seen that $\mathrm{pH}$ had a great influence on the response surface. It is well known that the catalyst will be dissociated into an acid-catalyzed state or a base-catalyzed state after bonding with the substrate, and only a few catalysts can have both two dissociation states [26]. Laccase belongs to this kind of catalyst with two dissociation states, that is, the active group of laccase can be dissociated into two different states of proton donor or proton acceptor, respectively [27]. The measured $\mathrm{pH}_{\mathrm{pzc}}$ of CKMB is 5.5-6, and the isoelectric point of laccase is approximately $\mathrm{pH}$ 3. Therefore, when the $\mathrm{pH}$ is between 2-3, the surfaces of laccase and CKMB are both positively charged, causing electrostatic repulsion. In addition, there is electrostatic attraction between the laccase and the carrier at $\mathrm{pH}$ range of 34. Therefore, the electrostatic attraction is strongest at $\mathrm{pH} \mathrm{4}$, and the enzyme loading reaches its maximum. However, the AR results of laccase@CKMB indicate that the dissociation state of the enzyme molecule at pH 3 fits best with the carrier, so that CKMB can retain laccase activity to the greatest extent [28]. The temperature had significant influence in the response (Fig. 5b and c), which meaned the AR of laccase@CKMB was very dependent on the temperature. Generally, in order to accelerate the enzymatic reaction or make the enzymatic reaction proceed smoothly, a certain temperature is often increased to provide sufficient energy (reaction activation energy) for the enzymatic reaction.However, under different temperature conditions, the activity of enzyme molecules may change significantly, which affects the 
catalytic reaction. If the temperature is too high (in this article, when the temperature exceeds $313 \mathrm{~K}$ ), the three-dimensional conformation of the enzyme may change, which means that some unstable groups may be oxidized with sufficient energy. In addition, too low temperature could also cause the enzyme activity to decrease or even dormancy, but it was not completely inactivated like at high temperature, because the structure of the enzyme has not changed. In addition, the predicted optimal experimental condition evaluation suggestion via Design-Expert 12 was about laccase dosage $1.78 \mathrm{mg} / \mathrm{mL}, \mathrm{pH} 3.1$ and $312 \mathrm{~K}$. Under these conditions, the activity recovery of laccase@CKMB was the highest, reaching 61.78\% .

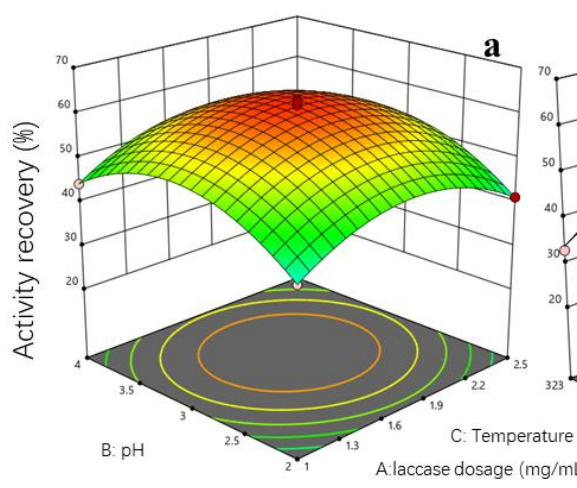

Factor Coding: Actual

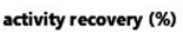
Design Points:

Above Surface

Below Surface

$30.61 \longrightarrow 63.02$

$\mathrm{X} 1=\mathrm{A}:$ laccase dosage

$\mathrm{X} 2=\mathrm{B}: \mathrm{pH}$

Actual Factor

C: temperature $=313$

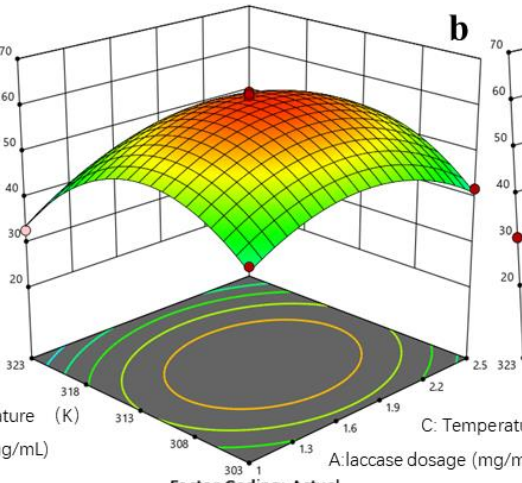

Factor Coding: Actua

activity recovery (\%)

Design Points:

- Above Surface

Below Surface

$30.61 \square 63.02$

$\mathrm{X} 1=\mathrm{A}:$ laccase dosage

$\mathrm{X} 2=\mathrm{C}:$ temperature

Actual Factor

B: $\mathrm{pH}=3$

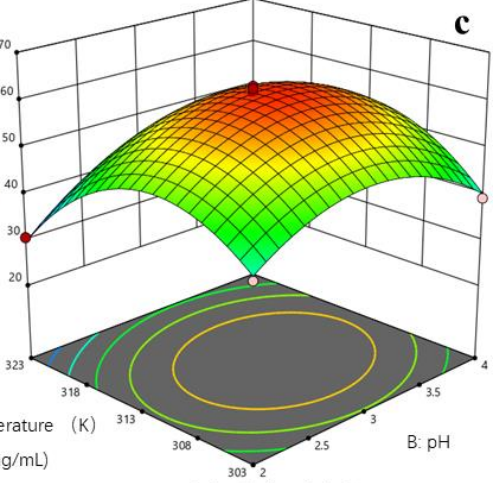

actor Coding: Actua

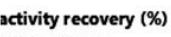

Design Points:

Above Surface

Below Surface

$3 0 . 6 1 \longdiv { \square } \square . 0 2$

$\mathrm{X} 1=\mathrm{B}: \mathrm{pH}$

$\mathrm{X} 2=\mathrm{C}$ : temperature

Actual Factor

A: laccase dosage $=1.75$

Fig. 5 (a) The effect of laccase dosage (A) and pH (B) on the immobilization effect. (b) The effect of laccase dosage (A) and temperature (C) on the immobilization effect. (c) The effect of $\mathrm{pH}(\mathrm{B})$ and temperature (C) on the immobilization effect.

\section{Stability of FL and laccase@CKMB}

\section{Storage, pH stability and reusability analysis}

As we all know, the storage stability of enzyme is an important factor to consider when developing robust biocatalysts. The storage stability was assessed by storing at $4{ }^{\circ} \mathrm{C}$ for 30 days, the RA of laccase@CKMB and FL was determined per few days. It was observed that the RA of FL was $20.19 \%$, and the RA of laccase@CKMB was 39.96 \% after 30 days as shown in Fig. 6a. The result indicated that the laccase@CKMB had better storage stability than FL. As shown in Fig. 6b, the trend of RA of FL and laccase@CKMB did not show significant difference within pH range of 2-8. FL reached the maximum activity at $\mathrm{pH} 5$, but laccase@CKMB reached the maximum relative activity at $\mathrm{pH} 4$. In actual production, 
although FL has excellent catalytic degradation ability, and the degradation products are clean and pollutionfree. However, FL cannot be recycled and reused, resulting in high costs. Immobilization is one of the important solutions to this problem, and reusability becomes an important evaluation index. The reusability of laccase@CKMB during 6 reaction cycles was investigated via ABTS as substrate. The results showed a almost half of the activity losss after 6 cycles and retained about $45.1 \%$ of RA (Fig. 6c).
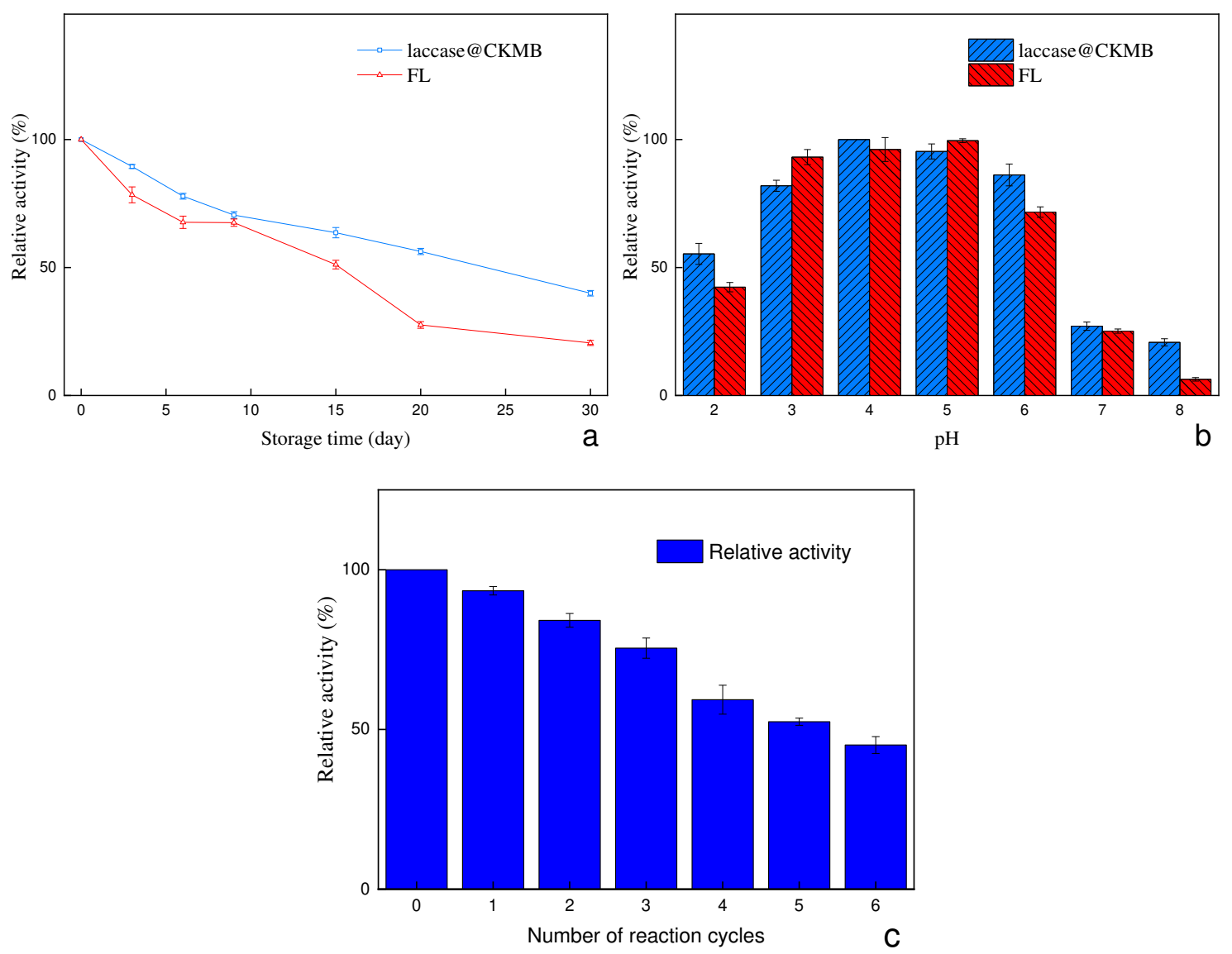

Fig. 6 (a) Storage stability of free laccase and laccase@ZIF-67. (b) The pH sability of FL and laccase@CKMB. (c) Reusability of laccase@CKMB.

\section{Thermostability and thermal deactivation kinetics model}

As shown in Fig. 7a, we determined the RA change at 293-338 K, it was observed that the RA of laccase@CKMB was greater than 50\%, and the maximum RA was obtained at $328 \mathrm{~K}$; The minimum RA of FL was about $35 \%$, and the maximum RA was obtained at 308-313 K. The Thermal deactivation kinetics fitting curve and thermal tolerance of FL and laccase@CKMB at $333 \mathrm{~K}$ was shown in Fig. 7b. The thermal tolerance of the laccase@CKMB was significantly better than that of FL. The RA of FL and laccase@CKMB both showed a significant downward trend with time. However, the rate of decrease in RA of FL was significantly greater than that of MBL. The RA of FL (33.6\%) and laccase@CKMB (60.1\%) reached a 

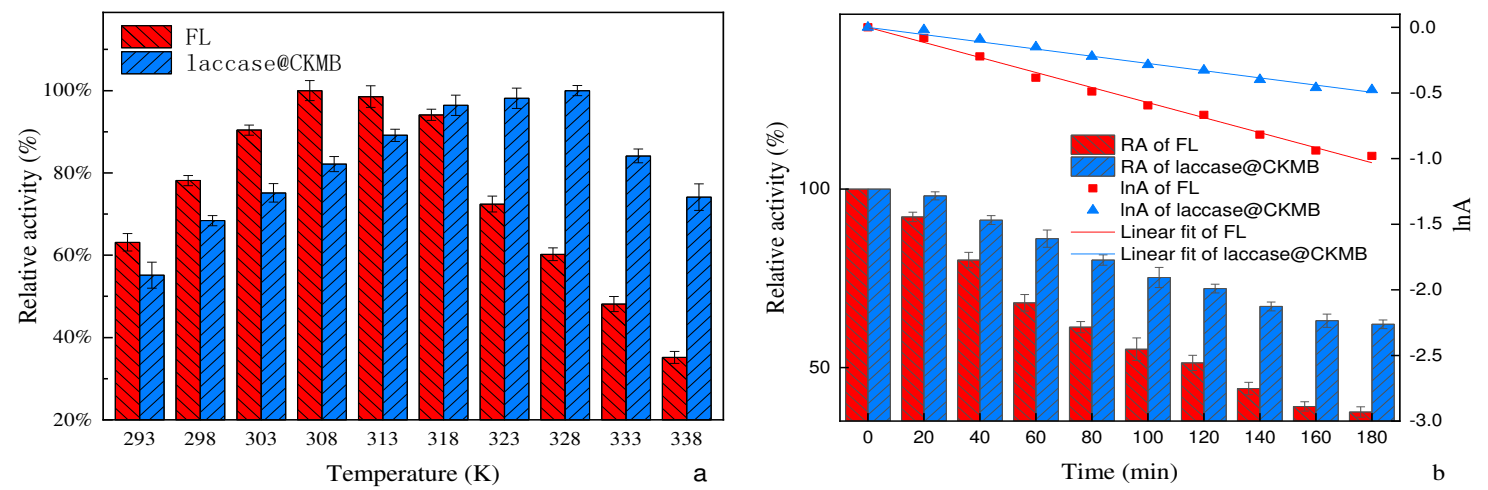

Fig. 7 (a) Thermostability of FL and laccase@CKMB. (b) Thermal deactivation kinetics fitting curve and thermal tolerance of FL and laccase@CKMB (333 K).

Table 4 depicted the comparison of deactivation rate constants $(k)$, half-life $\left(t_{1 / 2}\right)$, and the $R$ value of FL and laccase@CKMB at $333 \mathrm{~K}$. The k value of laccase@CKMB (0.00275)was much lower when compared to FL (0.00573), which also conferred 2 folds enhanced half-life than that of FL. In addition, the experimental data obtained for both FL and laccase@CKMB were adequately represented via the first-order model in Fig. 7b, with an excellent correlation for both curves $\left(\mathrm{R}^{2}=0.998\right.$ and 0.996 for FL and laccase@CKMB, respectively).

Table 4 Thermal deactivation kinetics model parameters for FL and laccase@CKMB at 333 K.

\begin{tabular}{ccc}
\hline Method & FL & laccase@CKMB \\
\hline $\mathrm{k}\left(\mathrm{min}^{-1}\right)$ & 0.00573 & 0.00275 \\
$\mathrm{t}_{1 / 2}(\min )$ & 121.0 & 252.0 \\
$\mathrm{R}$ & 0.998 & 0.996 \\
\hline
\end{tabular}

\section{The comparison of enzymatic parameters of different immobilized}

The results of enzyme loading, activity recovery and stability of the immobilized laccase are compared with the results of similar research previously reported in the literature of recent years (Table 5). In recent years, there are few data about the enzyme loading and activity recovery of immobilized laccase reported in the relevant literature, but it also can be seen from Table 5 that the enzyme loading $(57.5 \mathrm{mg} / \mathrm{g})$ and activity recovery $(61.78 \%)$ of this study is comparable to the data reported in other studies. For the comparison of stability, we pioneered the design of a stability comparison method, which is to compare stability parameters 
greater than $50 \%$ in the relevant literature. It can be inferred from Table 5 that laccase@CKMB has a good storage stability and thermal stability, and possesses a wide $\mathrm{pH}$ range and multiple reuse times. It is worth noting that the carrier used in this study is prepared from agricultural solid waste-rice straw, and the CKMB has the advantages of low cost and easy preparation. The above conclusions all prove the potential of laccase@CKMB in industrial applications (such as wastewater treatment, dye bleaching, etc.).

Table 5 The comparison of enzymatic parameters of different immobilized laccases

\begin{tabular}{|c|c|c|c|c|c|c|c|c|}
\hline Carrier & $\begin{array}{c}\text { polyacrylonitri } \\
\text { le-biochar }\end{array}$ & $\begin{array}{c}\text { pinewood } \\
\text { nanobiocha } \\
\mathrm{r}\end{array}$ & $\mathrm{Fe}_{3} \mathrm{O}_{4} @ \mathrm{ZIF}-8$ & $\begin{array}{l}\text { calcium/coppe } \\
\text { r alginate } \\
\text { beads }\end{array}$ & E-CLEA & $\begin{array}{c}\text { PVDF/MWCN } \\
\text { T membrane }\end{array}$ & $\begin{array}{c}\text { polyacrylamide } \\
\text {-alginate } \\
\text { cryogel }\end{array}$ & $\begin{array}{c}\text { CTAB- } \\
\mathrm{KOH} \\
\text { modified } \\
\text { biochar }\end{array}$ \\
\hline Year & 2017 & 2018 & 2019 & 2019 & 2019 & 2021 & 2021 & 2021 \\
\hline Source of Laccase & $\begin{array}{l}\text { Trametes } \\
\text { versicolor }\end{array}$ & $\begin{array}{l}\text { Trametes } \\
\text { versicolor }\end{array}$ & $\begin{array}{c}B . \\
\text { amyloliquefacien } \\
s \mathrm{LC} 22\end{array}$ & $\begin{array}{c}\text { Cyberlindnera } \\
\text { fabianii }\end{array}$ & $\begin{array}{c}\text { Trametes } \\
\text { versicolo } \\
r\end{array}$ & $\begin{array}{c}\text { Trametes } \\
\text { hirsuta }\end{array}$ & $\begin{array}{l}\text { Trametes } \\
\text { versicolor }\end{array}$ & $\begin{array}{c}\text { Trametes } \\
\text { versicolo } \\
r\end{array}$ \\
\hline $\begin{array}{l}\text { Enzyme loading } \\
\qquad(\mathrm{mg} / \mathrm{g})\end{array}$ & 10.1 & - & - & - & - & 30.4 & 68.7 & 57.5 \\
\hline $\begin{array}{c}\text { Activity recovery } \\
(\%)\end{array}$ & - & - & 75.5 & 75 & - & 38.31 & - & 61.78 \\
\hline Stabilit Storage & $>30$ days & 25 days & $>10$ days & $>21$ days & $>20$ days & - & - & $>20$ days \\
\hline $\mathrm{pH}$ & $3-8$ & $3-5$ & - & $3-9$ & $4-5$ & - & $2.5-4$ & $2-6$ \\
\hline (RA > Thermal & $20-60{ }^{\circ} \mathrm{C}$ & $20-60{ }^{\circ} \mathrm{C}$ & $60-80{ }^{\circ} \mathrm{C}$ & $30-70{ }^{\circ} \mathrm{C}$ & $25-55^{\circ} \mathrm{C}$ & $20-70{ }^{\circ} \mathrm{C}$ & $30-70^{\circ} \mathrm{C}$ & $30-66{ }^{\circ} \mathrm{C}$ \\
\hline $50 \%$ ) Reuse & 6 cycles & 3 cycles & 5 cycles & 3 cycle & 20 cycles & 2 cycles & 7 cycles & 5 cycles \\
\hline Reference & [29] & [30] & [31] & [32] & [33] & [34] & [35] & $\begin{array}{l}\text { This } \\
\text { work }\end{array}$ \\
\hline
\end{tabular}

\section{Discussion}

When laccase dosage was $1.75 \mathrm{mg} / \mathrm{mL}$, the AR reached a maximum of $54.1 \%$, and then the AR showed a downward trend. This phenomenon indicated that the carrier was saturated due to excess enzyme in the solution. Similar observations had been made in previous study [36], they observed a decrease in the activity recovery of bentonite-derived mesoporous materials immobilized laccase when the laccase dosage exceeded $2 \mathrm{mg} / \mathrm{mL}$. The overload of FL on the surface of the carrier will cause the congestion or crowding of enzyme molecules [37]. The measured $\mathrm{pH}_{\mathrm{pzc}}$ of $\mathrm{CKMB}$ is 5.5-6, and the isoelectric point of laccase is approximately $\mathrm{pH}$ 3. Therefore, when the $\mathrm{pH}$ was between 2-3, the surfaces of FL and CKMB are both positively charged, which lead to the electrostatic repulsion between the laccase and the carrier; When the $\mathrm{pH}$ was between 36 , there was electrostatic attraction between the laccase and the carrier. As the $\mathrm{pH}$ increased, the negative 
charge of the laccase gradually increased, and the positive charge on the surface of the carrier gradually decreased. Therefore, when the $\mathrm{pH}$ is 4 , the electrostatic attraction is the strongest, and the enzyme loading reaches the maximum (38.2); When the $\mathrm{pH}$ was greater than 6 , the surfaces of the FL and CKMB were negatively charged, and there was electrostatic repulsion between laccase and carrier, so the adsorption capacity was reduced. There is no synchronization relationship between AR and enzyme loading, which was mainly because the load process of FL on CKMB was an endothermic reaction process. The increase in temperature provided more favorable conditions for the loading of laccase [38]. However, the increase in temperature lead to a rearrangement of the three-dimensional conformation of laccase, which meaned a decrease in enzyme activity.

The optimal pH of laccase@CKMB changed from 5 (FL) to 4 , indicating that an electrostatic interaction occurred between the protein and the matrix microenvironment. In addition, changes in the dissociation and ionization state of the enzyme during the immobilization process may have caused changes in $\mathrm{pH}$. Moreover, the decrease in the RA of both FL and laccase@CKMB at high pH (more than 7) could be attributed to the inhibition of the enzyme, which is caused by the bonding of the hydroxide ions to $\mathrm{Cu}$ of the active site of enzyme. On the other hand, the inappropriate $\mathrm{pH}$ of the solution might cause the amino acid originally inside the laccase to be exposed to the environment, which leads to a decrease in laccase activity. This indicated that laccase was more suitable for the pH range of 2-6, but laccase @ CKMB showed a higher tolerance under alkaline conditions. The reason for the general reusability may be that we used a milder physical adsorption method to immobilize laccase. Therefore, the binding force between FL and the active site of CKMB is not strong enough. After multiple reaction cycles and washing, a large amount of FL falled off the surface of CKMB, resulting in a decrease in enzyme activity. The similar decrease was reported by Imam et al., their rice straw biochar immobilized laccase demonstrated operational stability up to 6 cycles while retaining $40 \%$ of the RA [39]. However, due to the cheap and easy availability of CKMB and the gentle and simple immobilization method, the performance of laccase@CKMB was attractive enough, which also gave laccase@CKMB the potential for industrial applications.

As for thermostability, the RA range of FL changed significantly more than laccase@CKMB, this is because the laccase@CKMB can improve the stability of protein tertiary structure to a certain extent, thereby restricting the mobility of enzyme protein molecules in the system, so that laccase can still maintain high activity when the external environment temperature changes [40]. The results showed that the laccase@CKMB can protect the structural stability of the enzyme molecule. At high temperatures, the threedimensional conformation of the enzyme protein was prone to multi-directional irregular stretching, which will expose some of its reactive groups and even active sites. This may lead to the polymerization of the protein, or the change of the spatial folding order, resulting in the inactivation of laccase. The immobilization 
of FL on CKMB reduces the fluidity of laccase to a certain extent, and indirectly improved the stability of laccase molecular conformation. At the same time, in the pore space of CKMB, the independent space where FL was located relatively lags behind the heat reaction process, which also played a certain protective effect on laccase protein and enhances its thermostability.

\section{Conclusion}

This paper explored the adsorption-immobilization of laccase using the CTAB-KOH modified rice straw biochar as a carrier. The surface microscopic characteristics and chemical group characteristics of CKMB and laccase@CKMB were studied by various characterization methods. In addition, we gave the optimal immobilization conditions for laccase@CKMB (the predicted optimal immobilization conditions via Design-Expert 12 were laccase dosage $1.78 \mathrm{mg} / \mathrm{mL}$, pH 3.1 and $312 \mathrm{~K}$ ), which had a good stability improvement. This provided the possibility of industrial application for the immobilization of laccase through this cheap and easily available carrier material.

\section{Methods}

\section{Chemicals}

Trametes versicolor laccase $(0.99 \mathrm{U} / \mathrm{mg})$ and (3-ethylbenzothiazoline-6-sulfonate) diammonium salt (ABTS, $\geq 98 \%$ ) were purchased from from Sigma-Aldrich. Bovine serum albumin (BSA), coomassie brilliant blue G-250, $\mathrm{KOH}$, cetyltrimethylammonium bromide (CTAB), phosphoric acid, sodium dihydrogen phosphate, disodium hydrogen phosphate were purchased from Sinopharm Group Chemical Reagent Co., Ltd (analytical grade). The rice straw comes from Lianyungang, Jiangsu Province.

\section{Characterization}

Perform thermogravimetric analysis (TGA) on a TGA55 thermal analyzer, and heat the sample in a continuous-flow of nitrogen (flow rate is $80 \mathrm{~mL} / \mathrm{min}$ ) at a rate of $10{ }^{\circ} \mathrm{C} / \mathrm{min}$ from 25 to $800{ }^{\circ} \mathrm{C}$. Fourier transform infrared spectroscopy (FT-IR) was performed on a Thermo Scientific Nicolet 6700 Fourier transform infrared spectrometer, and the scanning range was $4000 \mathrm{~cm}^{-1}-400 \mathrm{~cm}^{-1}$. X-ray diffraction (XRD) analysis was performed by Bruker D8A X-ray diffractometer using $\mathrm{Cu}-\mathrm{K} \alpha$ radiation (tube voltage: $40 \mathrm{KV}$; current: $40 \mathrm{~mA}$; scan angle $2 \theta$ range: 5 to $80^{\circ}$; scan rate: $5 \%$ min; wavelength: $0.15406 \mathrm{~nm}$ ). The nitrogen 
adsorption-desorption isotherm (BET) was measured on the TriStar II 3flex surface area and porosity analyzer. And the Scanning electron microscope (SEM) studies were carried out in a Zeiss Merlin Compact.

\section{Optimal immobilization conditions of CTAB-КОН modified biochar}

\section{immobilized laccase}

The modification of biochar was carried out by the method recorded in our previously published article [41]. In brief, The pretreated rice straw was heated to $600^{\circ} \mathrm{C}$ in a vacuum tube furnace and kept for 4 hours to prepare biochar. Then, the $\mathrm{KOH}$ activated biochar was placed in CTAB solution, stirred for $24 \mathrm{~h}$ and dried at $80{ }^{\circ} \mathrm{C}$ for $48 \mathrm{~h}$ to prepare $\mathrm{CTAB}-\mathrm{KOH}$ modified biochar (CKMB). In order to explore the optimal immobilization conditions of laccase immobilized on CKMB, a series of batch single-factor experiments were completed via adsorption method. 200mg of CKMB was added to $0.25-3 \mathrm{mg} / \mathrm{mL}$ laccase solution ( $\mathrm{pH}$ 2-8), then the mixture was shaken at 293-338 $\mathrm{K}$ for $4 \mathrm{~h}$. At last, the centrifuged precipitate was dried at 313 $\mathrm{K}$ for $48 \mathrm{~h}$ to determine the enzyme loading and enzyme activity. Then, the response surface methodology (RSM) and 3-factor Box-Behnken design via Design-Expert 12 (Stat-Ease, Inc, Minneapolis, MN 55413, USA) were used to optimize the immobilization conditions of laccase, where laccase dosage (A), pH (B) and temperature $(\mathrm{C})$ were the 3 independent factors selected for the activity recovery of immobilized laccase (Y) as design response.

\section{Determination of enzyme loading and enzyme activity}

The BSA was used as the standard protein, the protein concentration in the enzymatic extracts was determined by the Bradford method [42]. The absorbance at $595 \mathrm{~nm}$ was measured on a UV-2550 UV-Vis Spectrophotometer after 5-20 min. The absorbance showed a good linear relationship with the concentration of standard protein solution, the correlation coefficient $R^{2}$ was 0.9985 , and the fitting curve was $y=0.04557 x$ +0.0366 (Fig. 8). The calculation formula of enzyme loading is as follows:

$$
G=\frac{\left(C_{0}-C_{1}\right) \cdot V}{M}
$$

where $\mathrm{G}$ is the enzyme loading $(\mathrm{mg} / \mathrm{g}), \mathrm{C}_{0}$ is the initial protein concentration $(\mathrm{mg} / \mathrm{mL}), \mathrm{C}_{1}$ is the protein concentration in the supernatant $(\mathrm{mg} / \mathrm{mL}), \mathrm{V}$ is the initial protein solution volume $(\mathrm{mL})$, and the $\mathrm{M}$ is the mass of the prepared immobilized laccase $(\mathrm{g})$. 


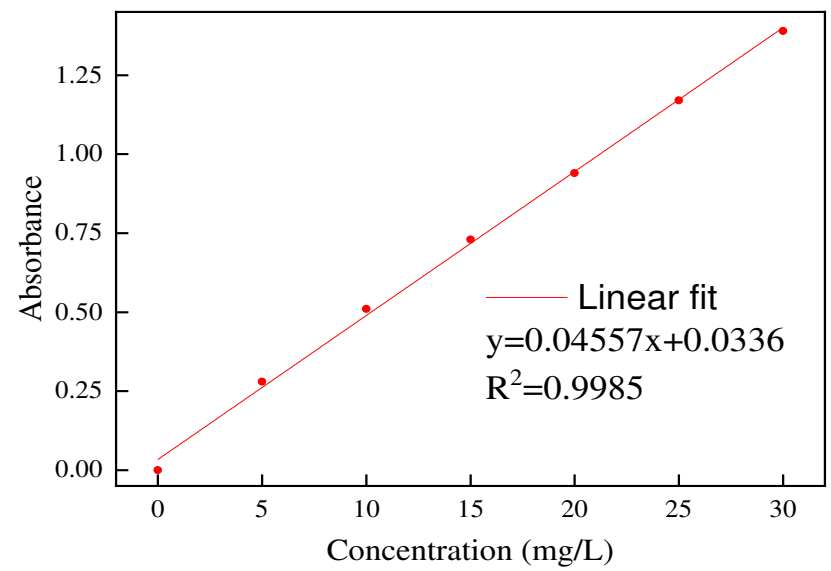

Fig. 8 The fitting curve of standard enzyme solution (BSA)

The activity of laccase was determined by monitoring the oxidation of ABTS substrate $(0.5 \mathrm{mmol} / \mathrm{L}$ ABTS). The reaction mixture ( $1.5 \mathrm{~mL}$ of $\mathrm{H}_{3} \mathrm{PO}_{4} / \mathrm{Na}_{2} \mathrm{HPO}_{4}$ buffer solution, $1 \mathrm{~mL}$ of enzyme solution and 0.5 $\mathrm{mL}$ ABTS) was incubated for $3 \mathrm{~min}$ in room temperature. The absorbance value of the mixed solution at 420 nm was immediately measured, and the activity was calculated by the Lambert-Beer principle [43]. Generally, an activity unit (U) is defined as the amount of enzyme required to consume $1 \mu \mathrm{mol}$ of substrate in 1 minute [44]. The calculation formula of specific activity (SA, U/mg), activity recovery (AR, \%) and relative activity (RA, \%) of laccase is as follows:

$$
\begin{aligned}
& \mathrm{SA}=\frac{A}{m} \\
& \mathrm{AR}=\frac{S A_{i}}{S A_{f}} \times 100 \% \\
& \mathrm{RA}=\frac{A}{A_{\max }} \times 100 \%
\end{aligned}
$$

Where $\mathrm{A}(\mathrm{U})$ is th activity of laccase, and $\mathrm{m}(\mathrm{mg})$ is the mass of free laccase (FL) or the enzyme amount of the CTAB-KOH modified biochar immobilized laccase (laccase@CKMB); $\mathrm{SA}_{\mathrm{i}}(\mathrm{U} / \mathrm{mg})$ is the specific activity of laccase@CKMB and $\mathrm{SA}_{\mathrm{f}}(\mathrm{U} / \mathrm{mg})$ is the specific activity of FL; $A m a x(U)$ is the maximum activity measured from this set of experiments.

\section{Stability of FL and laccase@CKMB}

The relative activity (RA) of FL and laccase@CKMB was measured at $4{ }^{\circ} \mathrm{C}$ per 5 days, and the RA within 30 days reflected the storage stability. The pH stabilities of FL and laccase@CKMB were compared by immersing them in $\mathrm{H}_{3} \mathrm{PO}_{4} / \mathrm{Na}_{2} \mathrm{HPO}_{4}$ buffer solution in the $\mathrm{pH}$ range $2-8$ for $1 \mathrm{~h}$ at room temperature. The reusability of laccase@CKMB was investigated in the catalytic oxidation reaction of ABTS with laccase for 
6 reaction cycles. FL and laccase@CKMB were subjected to heat treatment in a water bath at different temperatures (293 K-338 K). The RA of FL and laccase@CKMB was measured to determine thermostability. In addition, the FL and laccase@CKMB were kept in a 333K water bath for $3 \mathrm{~h}$ (enzyme activity was measured every 20 minutes) to obtain the thermal deactivation kinetics model, which was given to study their thermal tolerance.

The thermal deactivation of laccase was described as a "one step-two states" process where the active form was transformed in inactive form by a first order unimolecular irreversible reaction [45]. Therefore, the thermal deactivation kinetics model of FL and laccase@CKMB was described by the simple exponential equation of a first-order process. In addition, the half life $\left(t_{1 / 2}\right)$ of the enzyme activity was next estimated at $333 \mathrm{~K}$.

\section{Abbreviations}

CTAB: cetyltrimethylammonium bromide

CKMB: CTAB-KOH modified biochar

laccase@CKMB: CKMB immobilize laccase

FL: free laccase

ABTS: (3-ethylbenzothiazoline-6-sulfonate) diammonium salt

BSA: Bovine serum albumin

TGA: Thermal gravimetric analyses

FT-IR: Fourier Transform Infrared Spectroscopy

XRD: X-ray diffraction

BET: $\mathrm{N}_{2}$ adsorption-desorption isotherms

SEM: Scanning electron microscope

AR: activity recovery 


\section{References}

1. Arora DS, Chander M, Gill PK: Involvement of lignin peroxidase, manganese peroxidase and laccase in degradation and selective ligninolysis of wheat straw. International Biodeterioration \& Biodegradation 2002, 50(2):115-120.

2. Madhavi V, Lele SS: Laccase: properties and applications. BioResources 2009, 4(4):1694-1717.

3. Yaropolov AI, Skorobogat'Ko OV, Vartanov SS, Varfolomeyev SD: Laccase. Applied Biochemistry and Biotechnology 1994, 49(3):257-280.

4. Reiss R, Ihssen J, Richter M, Eichhorn E, Schilling B, Thöny-Meyer L: Laccase versus laccase-like multi-copper oxidase: a comparative study of similar enzymes with diverse substrate spectra. PloS one 2013, 8(6):e65633.

5. Hublik G, Schinner F: Characterization and immobilization of the laccase from Pleurotus ostreatus and its use for the continuous elimination of phenolic pollutants. Enzyme and microbial technology 2000, 27(3-5):330-336.

6. $\mathrm{Wu} \mathrm{Y,} \mathrm{Teng} \mathrm{Y,} \mathrm{Li} \mathrm{Z,} \mathrm{Liao} \mathrm{X,} \mathrm{Luo} \mathrm{Y:} \mathrm{Potential} \mathrm{role} \mathrm{of} \mathrm{polycyclic} \mathrm{aromatic}$ hydrocarbons (PAHs) oxidation by fungal laccase in the remediation of an aged contaminated soil. Soil Biology and Biochemistry 2008, 40(3):789-796.

7. Guardado ALP, Belleville M-P, Alanis MdJR, Saldivar RP, Sanchez-Marcano J: Effect of redox mediators in pharmaceuticals degradation by laccase: A comparative study. Process Biochemistry 2019, 78:123-131.

8. Wen X, Zeng Z, Du C, Huang D, Zeng G, Xiao R, Lai C, Xu P, Zhang C, Wan J: Immobilized laccase on bentonite-derived mesoporous materials for removal of tetracycline. Chemosphere 2019, 222:865-871.

9. Thiyagarajan P, Selvam K, Sudhakar C, Selvankumar T: Enhancement of Adsorption of Magenta Dye by Immobilized Laccase on Functionalized Biosynthesized Activated Carbon Nanotubes. Water, Air, \& Soil Pollution 2020, 231(7): 1-9.

10. Wang Z, Ren D, Yu H, Jiang S, Zhan S, Zhang X: Study on improving the stability of adsorption-encapsulation immobilized Laccase@ZIF-67. Biotechnology Reports 2020:e0553.

11. Chen X, Zhou Q, Liu F, Peng Q, Teng P: Removal of nine pesticide residues from water and soil by biosorption coupled with degradation on biosorbent immobilized laccase. Chemosphere 2019, 233:49-56. 
12. Wang Z, Ren D, Zhao Y, Huang C, Zhang S, Zhang X, Kang C, Deng Z, Guo H: Remediation and improvement of 2, 4-dichlorophenol contaminated soil by biocharimmobilized laccase. Environmental Technology 2019:1-14.

13. Alver E, Metin AÜ: Chitosan based metal-chelated copolymer nanoparticles: laccase immobilization and phenol degradation studies. International Biodeterioration \& Biodegradation 2017, 125:235-242.

14. Jin H, Hanif MU, Capareda S, Chang Z, Huang H, Ai Y: Copper (II) removal potential from aqueous solution by pyrolysis biochar derived from anaerobically digested algae-dairy-manure and effect of $\mathbf{K O H}$ activation. Journal of Environmental Chemical Engineering 2016, 4(1):365-372.

15. Peng H, Gao P, Chu G, Pan B, Peng J, Xing B: Enhanced adsorption of Cu (II) and Cd (II) by phosphoric acid-modified biochars. Environmental Pollution 2017, 229:846-853.

16. Taheran M, Naghdi M, Brar SK, Knystautas EJ, Verma M, Surampalli RY: Degradation of chlortetracycline using immobilized laccase on Polyacrylonitrilebiochar composite nanofibrous membrane. Science of The Total Environment 2017, 605-606:315-321.

17. Li N, Xia Q, Niu M, Ping Q, Xiao H: Immobilizing laccase on different species wood biochar to remove the chlorinated biphenyl in wastewater. Scientific reports 2018, 8(1):1-9.

18. Kashefi S, Borghei SM, Mahmoodi NM: Covalently immobilized laccase onto graphene oxide nanosheets: Preparation, characterization, and biodegradation of azo dyes in colored wastewater. Journal of Molecular Liquids 2019, 276:153-162.

19. Kaniyoor A, Baby TT, Ramaprabhu S: Graphene synthesis via hydrogen induced low temperature exfoliation of graphite oxide. Journal of Materials Chemistry 2010, 20(39):8467-8469.

20. Aydemir T, Güler S: Characterization and immobilization of Trametes versicolor laccase on magnetic chitosan-clay composite beads for phenol removal. Artificial Cells, Nanomedicine, and Biotechnology 2015, 43(6):425-432.

21. Ilk S, Demircan D, Sağlam S, Sağlam N, Rzayev ZMO: Immobilization of laccase onto a porous nanocomposite: application for textile dye degradation. Turkish Journal of Chemistry 2016, 40(2):262-276.

22. Sousa DVd, Guimarães LM, Félix JF, Ker JC, Schaefer CERG, Rodet MJ: Dynamic of the structural alteration of biochar in ancient Anthrosol over a long timescale by Raman spectroscopy. PloS one 2020, 15(3):e0229447.

23. Lonappan L, Liu Y, Rouissi T, Pourcel F, Brar SK, Verma M, Surampalli RY: Covalent immobilization of laccase on citric acid functionalized micro-biochars derived from different feedstock and removal of diclofenac. Chemical Engineering Journal 2018, 351:985-994.

24. García - Delgado C, Eymar E, Camacho - Arévalo R, Petruccioli M, Crognale S, D'Annibale A: Degradation of tetracyclines and sulfonamides by stevensite - and 
biochar - immobilized laccase systems and impact on residual antibiotic activity. Journal of Chemical Technology \& Biotechnology 2018, 93(12):3394-3409.

25. Zhang C, Hu C, Zhao Y, Möller M, Yan K, Zhu X: Encapsulation of laccase in silica colloidosomes for catalysis in organic media. Langmuir 2013, 29(49):1545715462.

26. Feng L, Ge X-P, Wang D-S, Tang H-X: Effects of pH value on the adsorption and degradation of 2, 4-DCP by nanoscale zero-valent iron. Huan jing ke xue= Huanjing kexue 2012, 33(1):94-103.

27. Huang J, Liu C, Xiao H, Wang J, Jiang D, Gu E: Zinc tetraaminophthalocyanine-Fe3O4 nanoparticle composite for laccase immobilization. International journal of nanomedicine 2007, 2(4):775.

28. Jia Y, Chen Y, Luo J, Hu Y: Immobilization of laccase onto meso-MIL-53 (Al) via physical adsorption for the catalytic conversion of triclosan. Ecotoxicology and environmental safety 2019, 184:109670.

29. Taheran M, Naghdi M, Brar SK, Knystautas EJ, Verma M, Surampalli RY: Degradation of chlortetracycline using immobilized laccase on Polyacrylonitrilebiochar composite nanofibrous membrane. Science of The Total Environment 2017, 605:315-321.

30. Naghdi M, Taheran M, Brar SK, Kermanshahi-pour A, Verma M, Surampalli RY: Pinewood nanobiochar: A unique carrier for the immobilization of crude laccase by covalent bonding. International Journal of Biological Macromolecules 2018, 115:563571.

31. Wang J, Yu S, Feng F, Lu L: Simultaneous purification and immobilization of laccase on magnetic zeolitic imidazolate frameworks: Recyclable biocatalysts with enhanced stability for dye decolorization. Biochemical Engineering Journal 2019, 150: 107285 .

32. Olajuyigbe FM, Adetuyi OY, Fatokun CO: Characterization of free and immobilized laccase from Cyberlindnera fabianii and application in degradation of bisphenol A. International Journal of Biological Macromolecules 2019, 125:856-864.

33. Fathali Z, Rezaei S, Faramarzi MA, Habibi-Rezaei M: Catalytic phenol removal using entrapped cross-linked laccase aggregates. International journal of biological macromolecules 2019, 122:359-366.

34. Masjoudi M, Golgoli M, Ghobadi Nejad Z, Sadeghzadeh S, Borghei SM: Pharmaceuticals removal by immobilized laccase on polyvinylidene fluoride nanocomposite with multi-walled carbon nanotubes. Chemosphere 2021, 263:128043.

35. Yavaşer R, Karagözler AA: Laccase immobilized polyacrylamide-alginate cryogel: A candidate for treatment of effluents. Process Biochemistry 2021, 101:137146.

36. Wen X, Zeng Z, Du C, Huang D, Zeng G, Xiao R, Lai C, Xu P, Zhang C, Wan J et al: Immobilized laccase on bentonite-derived mesoporous materials for removal of tetracycline. Chemosphere 2019, 222:865-871. 
37. Jankowska K, Zdarta J, Grzywaczyk A, Kijeńska-Gawrońska E, Biadasz A, Jesionowski T: Electrospun poly (methyl methacrylate)/polyaniline fibres as a support for laccase immobilisation and use in dye decolourisation. Environmental Research 2020:109332.

38. Durao P, Bento I, Fernandes AT, Melo EP, Lindley PF, Martins LO: Perturbations of the $\mathrm{T1}$ copper site in the CotA laccase from Bacillus subtilis: structural, biochemical, enzymatic and stability studies. JBIC Journal of Biological Inorganic Chemistry 2006, 11(4):514-526.

39. Imam A, Suman SK, Singh R, Vempatapu BP, Ray A, Kanaujia PK: Application of laccase immobilized rice straw biochar for anthracene degradation. Environmental Pollution 2020, 268:115827.

40. Reiss R, Ihssen J, Thöny-Meyer L: Bacillus pumilus laccase: a heat stable enzyme with a wide substrate spectrum. BMC biotechnology 2011, 11(1):1-11.

41. Ren $\mathrm{D}$, Yu H, Wu J, Wang Z, Zhang S, Zhang X, Gong X: The study on adsorption behavior of 2, 4-DCP in solution by biomass carbon modified with CTABKОH. Water Science and Technology 2020, 82(8):1535-1546.

42. Kruger NJ: The Bradford method for protein quantitation. In: The protein protocols handbook. Springer; 2009: 17-24.

43. Bourbonnais R, Leech D, Paice MG: Electrochemical analysis of the interactions of laccase mediators with lignin model compounds. Biochimica et Biophysica Acta (BBA)-General Subjects 1998, 1379(3):381-390.

44. Wang F, Guo C, Yang L-r, Liu C-Z: Magnetic mesoporous silica nanoparticles: Fabrication and their laccase immobilization performance. Bioresource Technology 2010, 101(23):8931-8935.

45. Aymard C, Belarbi A: Kinetics of thermal deactivation of enzymes: a simple three parameters phenomenological model can describe the decay of enzyme activity, irrespectively of the mechanism. Enzyme and microbial Technology 2000, 27(8):612-618. 46. Vasconcelos AFD, Barbosa AM, Dekker RFH, Scarminio IS, Rezende MI: Optimization of laccase production by Botryosphaeria sp. in the presence of veratryl alcohol by the response-surface method. Process Biochemistry 2000, 35(10):1131-1138.

47. Miyazaki K: A hyperthermophilic laccase from Thermus thermophilus HB27. Extremophiles 2005, 9(6):415-425.

\section{Acknowledgements}

$$
\text { We gratefully acknowledge financial support from Science and Technology Innovation Team Project }
$$
of Hubei Provincial Department of Education (Grant No. T2020002), Wuhan Science and Technology Planning Project (Grant No. 2020020601012274), National Natural Science Foundation of China (Grant No. 


\section{$542 \quad$ Funding}

This work was supported by Science and Technology Innovation Team Project of Hubei Provincial Department of Education (Grant No. T2020002), Wuhan Science and Technology Planning Project (Grant No. 2020020601012274), National Natural Science Foundation of China (Grant No. 41571306) and Hubei Technological Innovation Special Fund (Grant No. 2020ZYYD019).

\section{Author information}

\section{Affiliations}

College of Resource and Environmental Engineering, Wuhan University of Science and Technology, Wuhan, 430081, China

Zhaobo Wang, Dajun Ren, Shan Jiang, Hongyan Yu, Yaohui Cheng, Shuqin Zhang, Xiaoqing Zhang, Wangsheng Chen

Hubei Key Laboratory for Efficient Utilization and Agglomeration of metallurgic Mineral Resources, Wuhan University of Science and Technology, Wuhan, Hubei 430081, China

Zhaobo Wang, Dajun Ren, Shan Jiang, Hongyan Yu, Yaohui Cheng, Shuqin Zhang, Xiaoqing Zhang, Wangsheng Chen

\section{Contributions}

ZW contributed the Conceptualization, Methodology, Writing-Original draft preparation, Data curation. DR contributed the Conceptualization, Writing- Reviewing and Editing. JS, HY and CH contributed the Investigation. At last, SZ, XZ and WC contributed the Writing- Reviewing and Editing. All authors read and approved the final manuscript.

\section{Corresponding authors}

Correspondence to Dajun Ren 


\section{Ethics declarations}

565 Availability of data and materials

All data generated and analyzed in this study are included in this published article.

\section{Ethics approval and consent to participate}

$568 \quad$ Not applicable.

\section{Consent for publication}

$570 \quad$ Not applicable.

\section{Competing interests}

572 The authors declare that they have no competing interests. 
Figures

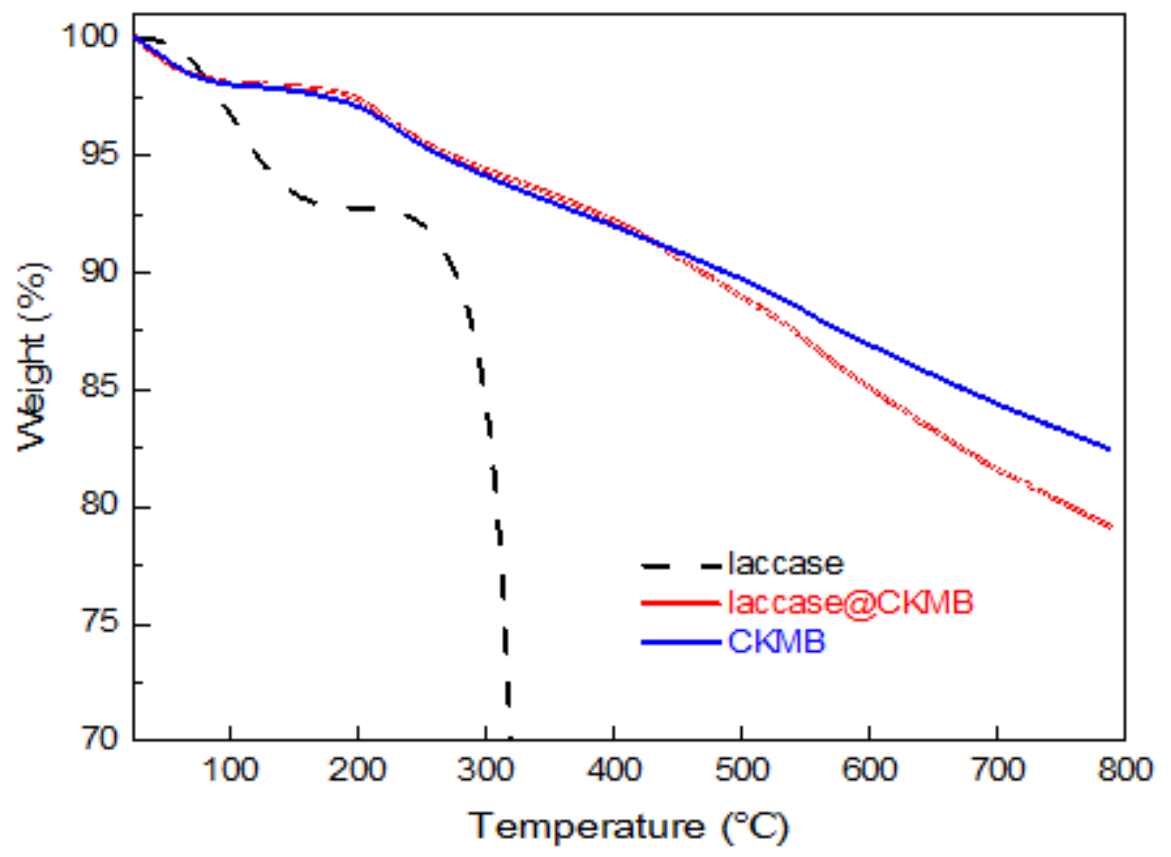

Figure 1

The TGA curve of CKMB and laccase@CKMB.
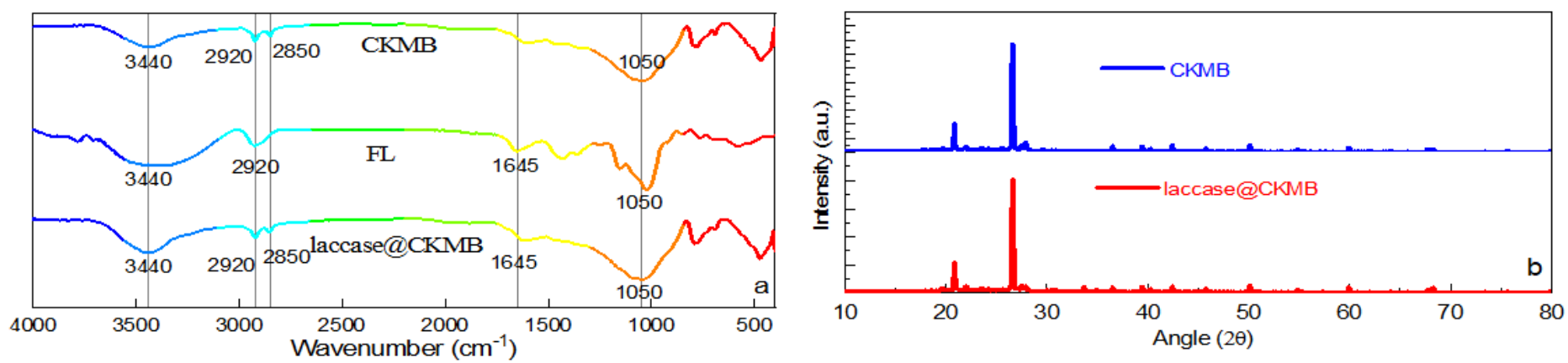

Figure 2

(a) The FTIR spectra of FL, CKMB and laccase@CKMB. (b) XRD patterns of CKMB and laccase@CKMB. 

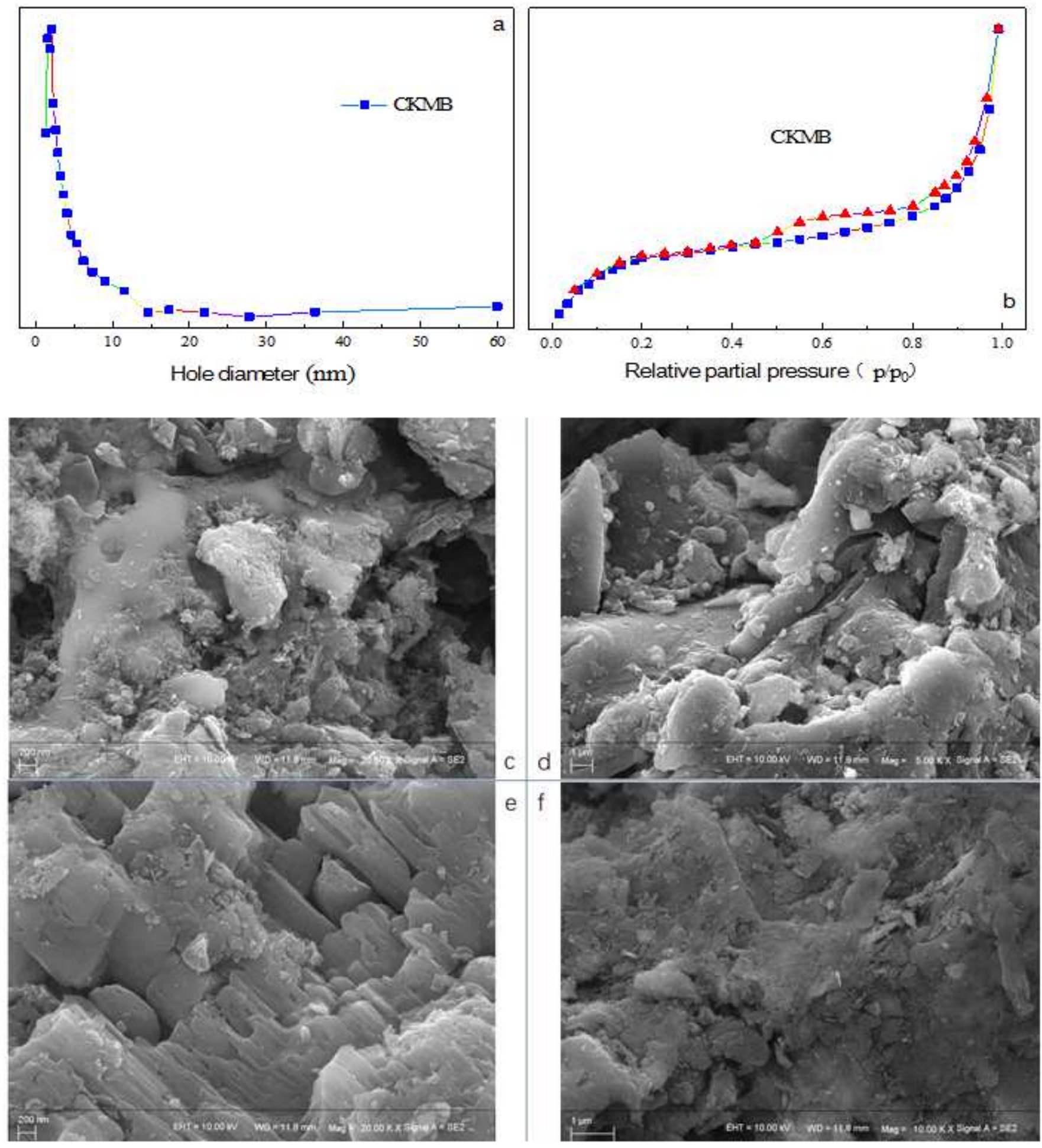

Figure 3

(a) The pore size distribution of CKMB. (b) The N2 adsorption-desorption curve of CKMB. Scanning electron micrograph of (c and d) CKMB, (e and f) laccase@CKMB. 

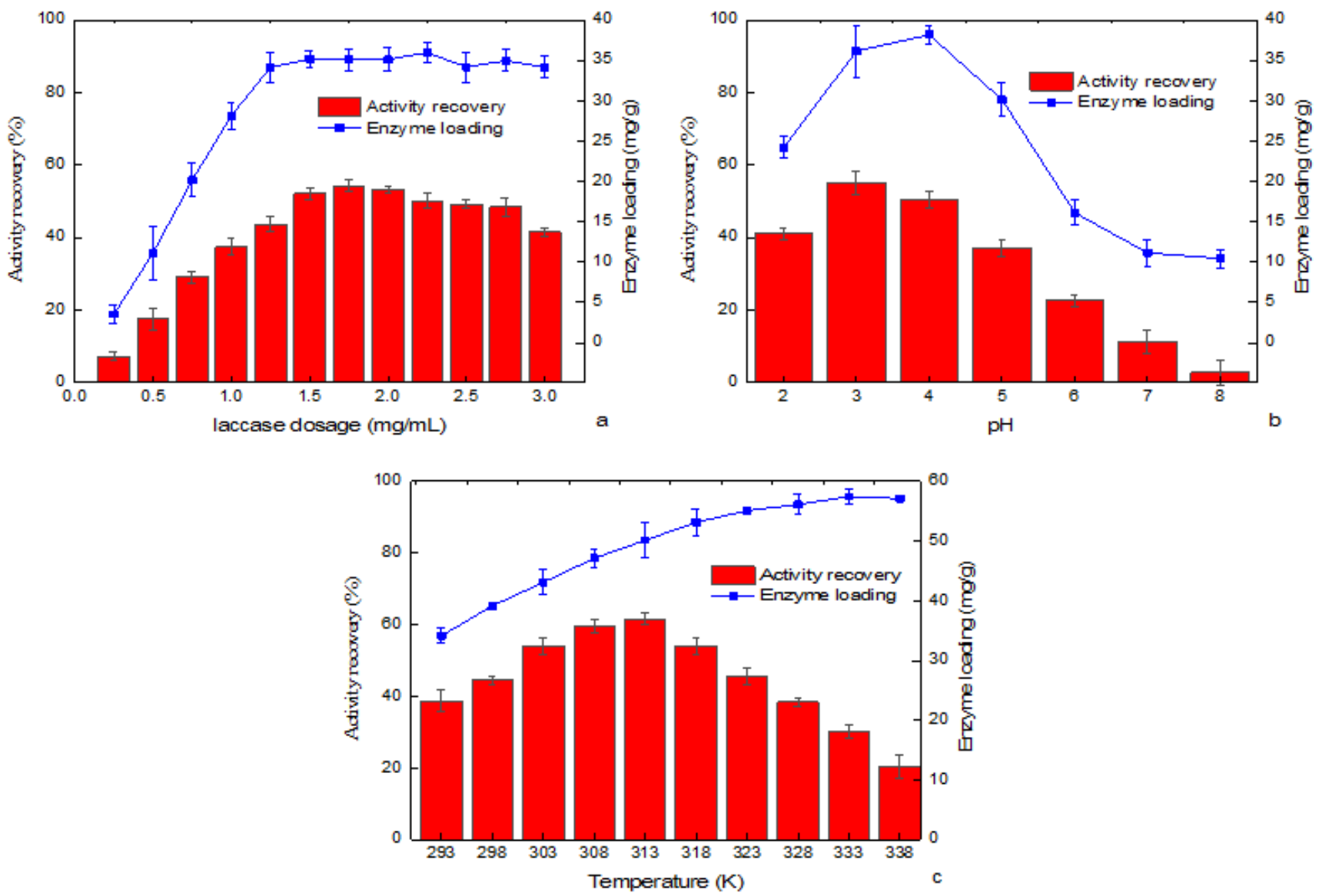

Figure 4

The effect of (a) laccase dosage, (b) pH and (c) temperature on the immobilization effect. 

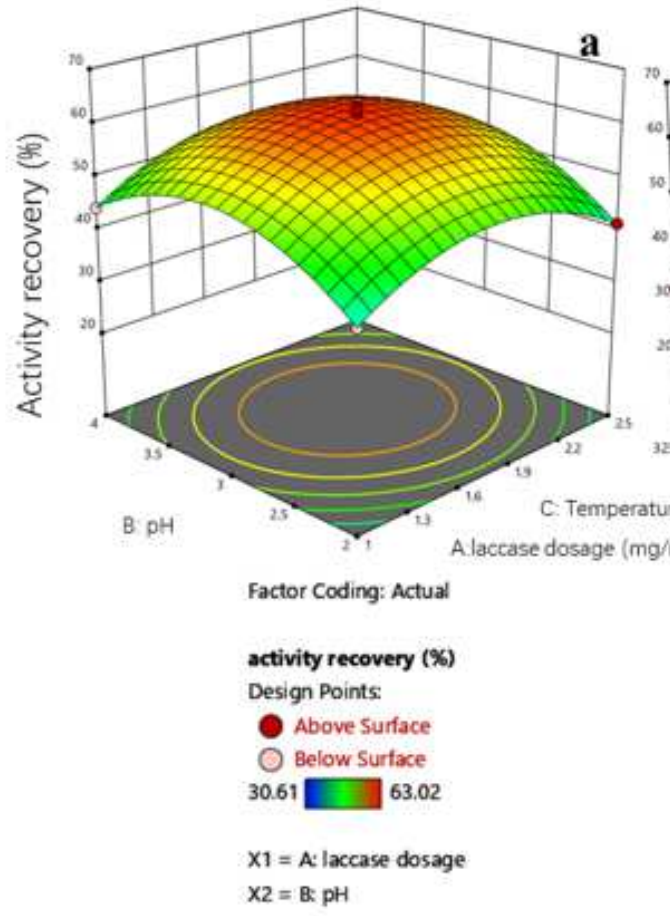

Actual Factor

C. temperature $=\mathbf{3 1 3}$

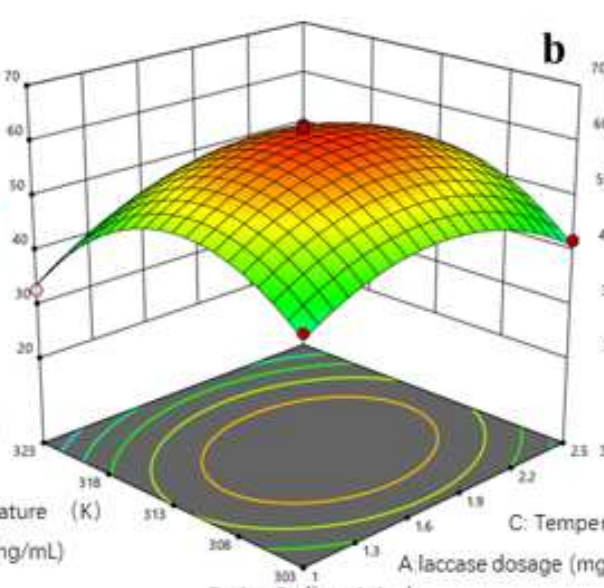

Factor Coding: Actual

$$
\begin{aligned}
& \text { activity recovery (\%) } \\
& \text { Design Points: } \\
& \text { Above Surface } \\
& \text { Below Surface } \\
& 30.61 .02 \\
& X 1=\text { A: laccase dosage } \\
& X 2=\text { C: temperature }
\end{aligned}
$$

Actual Factor

B. $\mathrm{pH}=3$

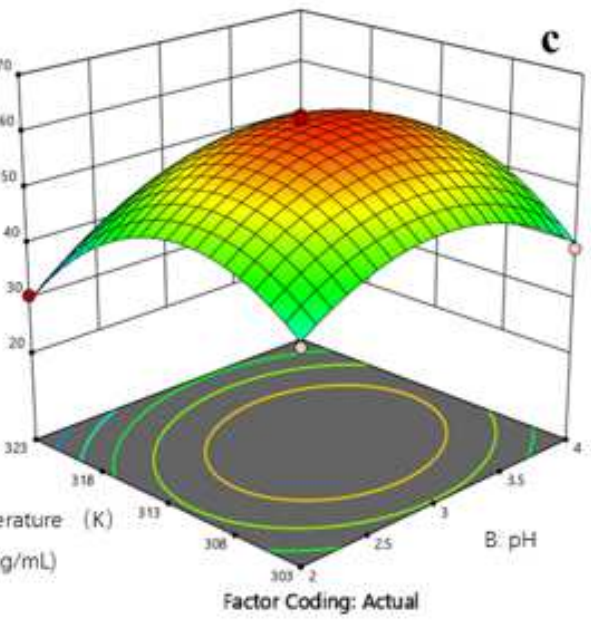

activity recovery (\%)

Design Points

- Above Surface

Below Surface

$30.61 \square 63.02$

$\mathrm{X}_{1}=\mathrm{B} \cdot \mathrm{pH}$

$\mathrm{X}_{2}=\mathrm{C}_{1}$ temperature

Actual Factor

Ac laccase dosage $=1.75$

\section{Figure 5}

(a) The effect of laccase dosage (A) and $\mathrm{pH}(\mathrm{B})$ on the immobilization effect. (b) The effect of laccase dosage (A) and temperature (C) on the immobilization effect. (C) The effect of $\mathrm{pH}(\mathrm{B})$ and temperature (C) on the immobilization effect.
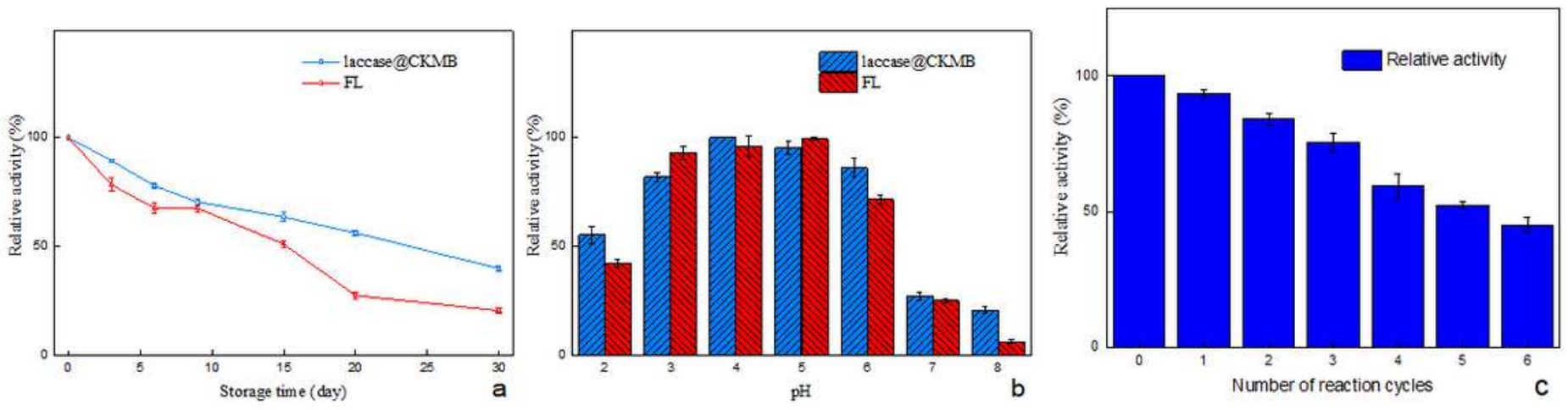

Figure 6

(a) Storage stability of free laccase and laccase@ZIF-67. (b) The pH sability of FL and laccase@CKMB.

(c) Reusability of laccase@CKMB. 

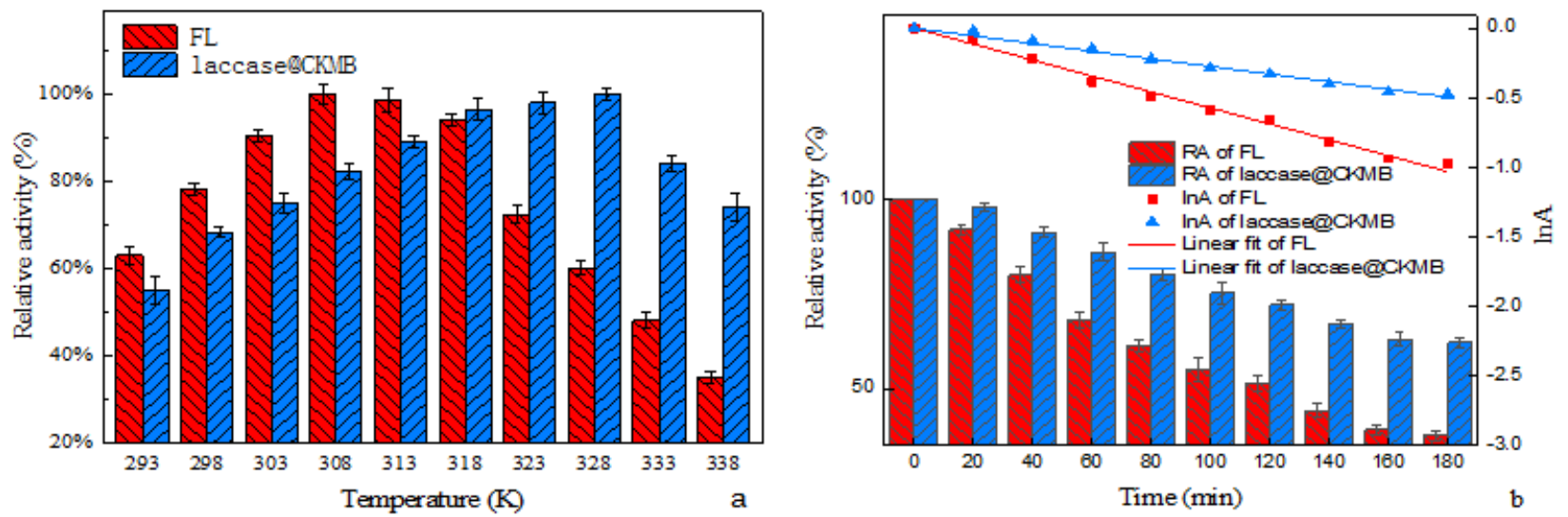

Figure 7

(a) Thermostability of FL and laccase@CKMB. (b) Thermal deactivation kinetics fitting curve and thermal tolerance of FL and laccase@CKMB (333 K).

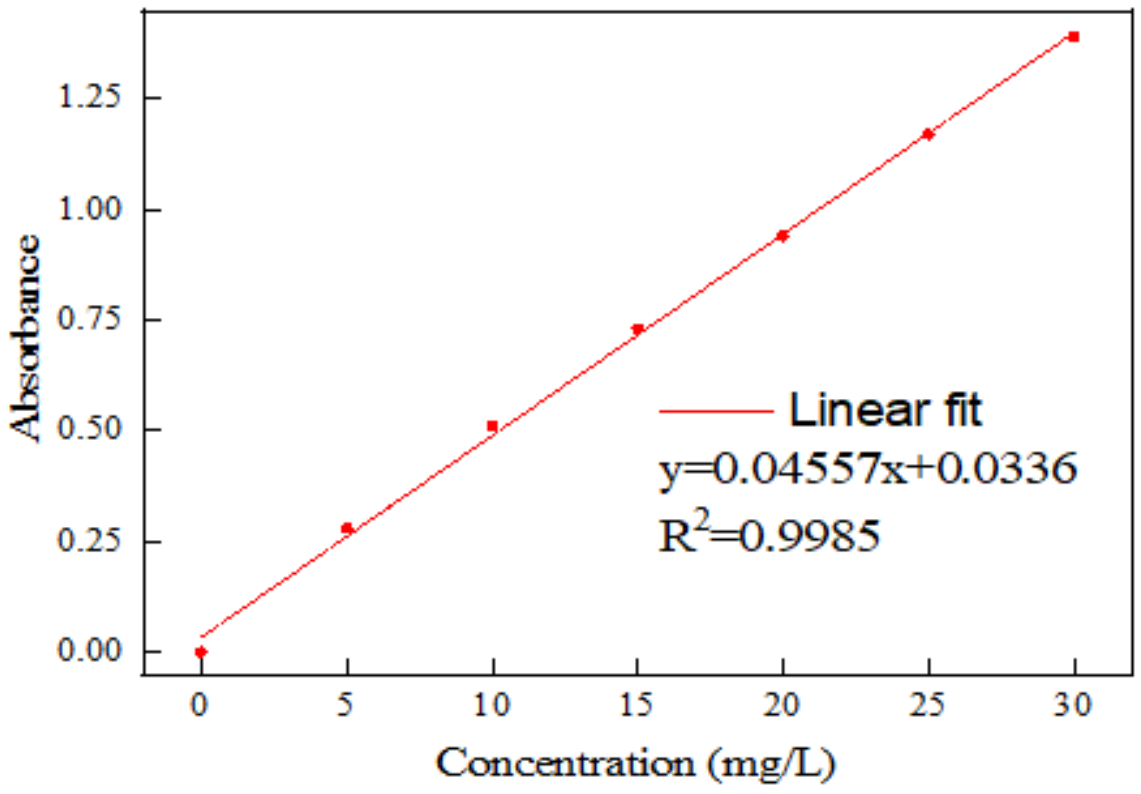

Figure 8

The fitting curve of standard enzyme solution (BSA). 